\title{
DISTRIBUIÇÃO DOS CHAETOGNATHA NO ATLÂNTICO SUL OCIDENTAL
}

(Recebido em 8/11/60)

M. S. de Almeida Prado

\section{INTRODUÇÃO}

Em prosseguimento aos trabalhos relativos aos Chaetognatha, fizemos o estudo da distribuição geográfica do grupo e de sua relação com as diferentes massas de águas.

Tivemos como principal objetivo neste trabalho conhecer as prováveis formas indicadoras e associações planctônicas das massas de água. Neste mesmo sentido, já foi feito, nesta região, um trabalho sôbre as Hydromedusae (Vannucci, 1957), de modo que nos foi possível relacionar a ocorrência simultânea das espécies dos dois grupos, com um determinado tipo de água.

Existem dados, embora raros, da ocorrência e distribuição geográfica dos Chaetognatha nesta região, mas não foi feito ainda nenhum estudo com o intuito de encontrar as espécies indicadoras. As únicas referências dêste grupo, nas costas brasileiras, são as da "Meteor" e "Liguria". A "British Antarctic Expedition" também coletou em águas brasileiras, porém sòmente na latitude do Rio de Janeiro é que a sua área de pesquisa coincide com a nossa.

O material estudado neste trabalho procede de várias viagens de pesquisa realizadas de junho de 1954 a novembro de 1956 pelo Instituto Oceanográfico, algumas delas em colaboração com a Marinha de Guerra Brasileira (Emílsson, 1956) .

Foram tomadas amostras numa faixa que se estende desde Cabo Frio até a latitude de Montevideu.

$\mathrm{Na}$ camada superficial da região investigada são encontradas três principais massas de água: água tropical oriunda das latitudes tropicais de salinidade entre 36 a $37,00 \%$, água da plataforma de salinidade entre 35 a $36,00 \%$ e água costeira de salinidade abaixo de $35,00 \%$ (Emílsson, 1959) .

Analisando êste material pudemos, até certo ponto, estabelecer as relações das diversas espécies com essas três massas de água.

Publ. n. 152 do Inst. Ocean. da USP. 
Na secção feita de Florianópolis para leste encontramos tôdas as espécies em grande quantidade. Nas secções feitas mais ao sul desta há uma notável diminuição do número de exemplares da maioria das espécies. A massa de água tropical perde temperatura e torna-se cada vez mais pobre em sais à medida que caminha para o sul. Possivelmente, é por isso que só as espécies fortemente euritérmicas foram coletadas na latitude de Montevideu.

Em águas da plataforma encontramos várias espécies típicas que parecem suportar maior variação de salinidade do que as da água tropical, pois, elas comparecem também nas duas massas de água adjacentes. Em águas costeiras encontramos uma única espécie característica e um menor número de espécies do que nas demais massas de água.

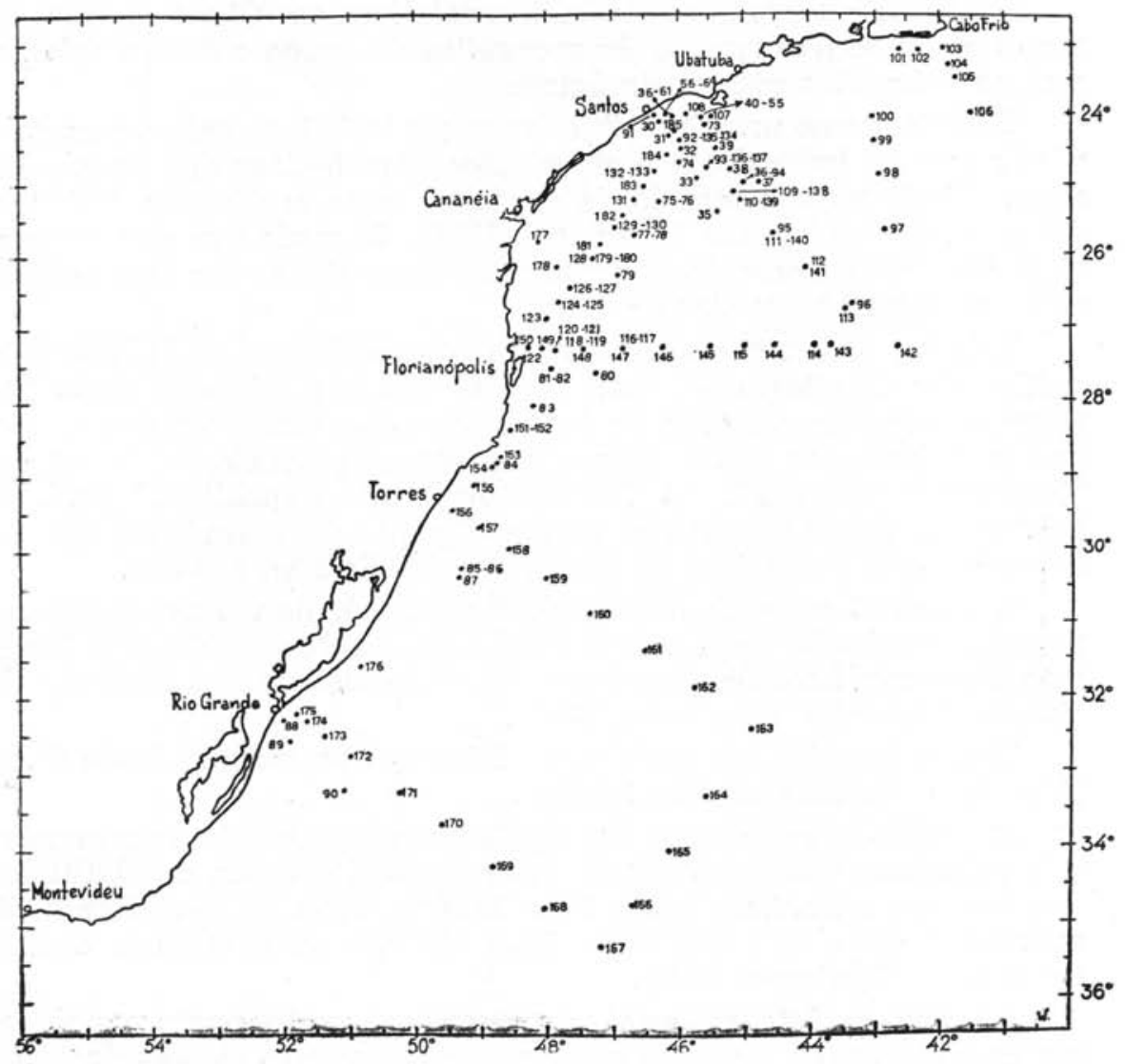

Fig. 1 - Mapa das estações feitas durante as viagens das corvetas "Solimões" e "Iguatemi", iate "Igaraty" e pesqueiro "Presidente Vargas". 
Nem tôdas as espécies demonstraram, neste material, uma distribuição homogênea mas sim uma tendência a formarem agrupamentos os quais chamamos cardumes.

Foram assinaladas no presente material dez espécies pertencentes a três gêneros: Sagitta bipunctata, $S$. enflata, $S$. friderici, $S$. gloriae, S. hispida, S. hexaptera, S. minima, S. serratodentata, Pterosagitta draco e Krohnitta pacifica.

Agradecimentos - Em primeiro lugar agradecemos à Dra. Marta Vannucci por tôdas as suas sugestões e orientação dêste trabalho. A Dra. Tagea K. S. Björnberg e Dr. Ingvar Emílsson agradecemos tôdas as suas sugestões. Ao Sr. João de Paiva Carvalho agradecemos a revisão do manuscrito. Somos gratas ainda à sra. Gilda Casari e Sr. Paulo Catunda pela separação e contagem de parte do material, ao sr. José Lupi e Sr. Caio Del Rio Garcia pela confecção de tabelas e gráficos. Agradecemos muito especialmente à Sra. Maria S. Björnberg pela tradução de textos alemães. A Marinha de Guerra Brasileira e aos funcionários do Instituto Oceanográfico agradecemos a colaboração prestada na coleta do material. Finalmente, somos gratas a todos que de algum modo nos auxiliaram durante a elaboração dêste trabalho.

\section{MATERIAL E MÉTODO}

O material que tivemos em mãos, embora abundante, não nos forneceu todos os dados desejáveis por terem sido usados meios diversos de coleta.

Infelizmente, a maioria das amostras não possui indicação sôbre o volume de água filtrado e por isso não foi possível fazer um estudo quantitativo. Entretanto, como o material foi abundante, pudemos fazer um estudo da predominância das espécies em cada massa de água, na tentativa de se chegar a discernir eventuais indicadores e de se iniciar o reconhecimento das associações de diferentes espécies.

O estudo sistematizado da variação anual e da migração vertical não foi feito porque coletamos uma única vez na maioria das estações. Mas, ao analisarmos as amostras em conjunto, nos foi possível encontrar alguns indícios tanto de variação como de migração.

Foram usados os seguintes tipos de rêde: Standard, ClarkeBumpus e rêde aberta com $50 \mathrm{~cm}$ de diâmetro na bôca.

O material coletado foi fixado em formol a $4 \%$ e as análises das amostras foram feitas através de contagens totais dos Chaetognatha sob lupa.

Os dados do local e da coleta, de salinidade e temperatura nos foram cedidos pela Divisão de Oceanografia Física. 
As coletas foram feitas, quase que na totalidade, em camadas superficiais, raramente atingindo $120 \mathrm{~m}$ de profundidade e, desta maneira, poucas vêzes coletando abaixo da termoclina.

Para a confecção dos gráficos (Figs. 14, 15, 16) foram utilizadas amostras provenientes de uma única massa de água tendo sido desprezadas àquelas que atravessaram mais de uma camada de água. Reunimos as amostras em três grupos segundo a sua proveniência: água costeira, da plataforma e tropical. Calculamos a quantidade porcentual de cada espécie por amostra e obtivemos três quadros diferentes da abundância relativa de cada espécie numa determinada massa de água.

Fizemos ainda gráficos (Figs. 4, 5, 8, 10,11) para relacionar a freqüência de indivíduos com a salinidade e temperatura.

\section{DISTRIBUIÇÃO DAS ESPÉCIES, SUAS ASSOCIAÇÕES E RELAÇõES COM AS MASSAS DE AGUA}

Sagitta bipunctata (Fig. 2) - Esta espécie não foi nem muito freqüente, nem muito abundante nesta região. Estêve presente em águas da plataforma e principalmente na água tropical (com mais de $36,00 \%$ de salinidade). Encontramos, como limite mínimo de salinidade, $35,37 \%$ e como limite máximo, 36,94\%. Em uma única estação de águas costeiras de $34,08 \%$ de salinidade $\left(\mathrm{M}_{122}\right)$ estiveram presentes dois exemplares desta espécie juntamente com $S$. serratodentata, S. minima e Pterosagitta draco que são animais típicos de água de alta salinidade. Isso nos leva a crer que êstes animais tenham migrado de camadas inferiores de salinidade mais alta, pois, a coleta foi feita às $2400 \mathrm{~h}$ a $10 \mathrm{~m}$ de profundidade, havendo a $59 \mathrm{~m}$ águas de $35,54 \%$ de salinidade. Sagitta bipunctata parece suportar grande variação de temperatura. Foram encontrados exemplares dessa espécie, principalmente, em águas de 14 a $22^{\circ} \mathrm{C}$ e sòmente raros indivíduos em águas mais quentes de 25 a $26^{\circ} \mathrm{C}$. A amostra $\mathrm{M}_{138}$ foi a mais abundante em $S$. bipunctata, sendo interessante no$\operatorname{tar}$ que ela foi coletada em águas mais frias $\left(14,37^{\circ} \mathrm{C}\right)$. S. bipunctata foi coletada desde $23^{\circ} 04^{\prime} \mathrm{S}$ até $33^{\circ} 12^{\prime} \mathrm{S}$. Estêve mais freqüente nas coletas feitas entre Santos e Florianópolis. Mais ao sul encontramo-la nas estações $\mathrm{M}_{161},{ }_{162},{ }_{163}$, 164, realizadas ainda em água tropical, associada a S. serratodentata, Aglaura hemistoma e Liriope tetraphylla. Parece ter uma distribuição anual uniforme.

Discussão - S. bipunctata já foi encontrada anteriormente nesta área: por Baldasseroni (1915, p. 89) no Rio Grande do Sul; por Thiel $(1938$, p. 32) na latitude do Rio de Janeiro e mais ao norte por Vannucci \& Hosoe (1952, p. 10) no Banco Jaseur e Ilha da Trindade. Os nossos dados parecem confirmar os de Vannucci \& Hosoe (1952, p. 10), e por êles podemos concluir que a espécie é oceânica 
e vive em águas de alta salinidade. Faure $(1952$, p. 36) considera $S$. bipunctata espécie oceânica de águas quentes e alta salinidade, superior a $36,00 \%$. Pierce $(1953$, p. 83$)$ encontrou S. bipunctata em

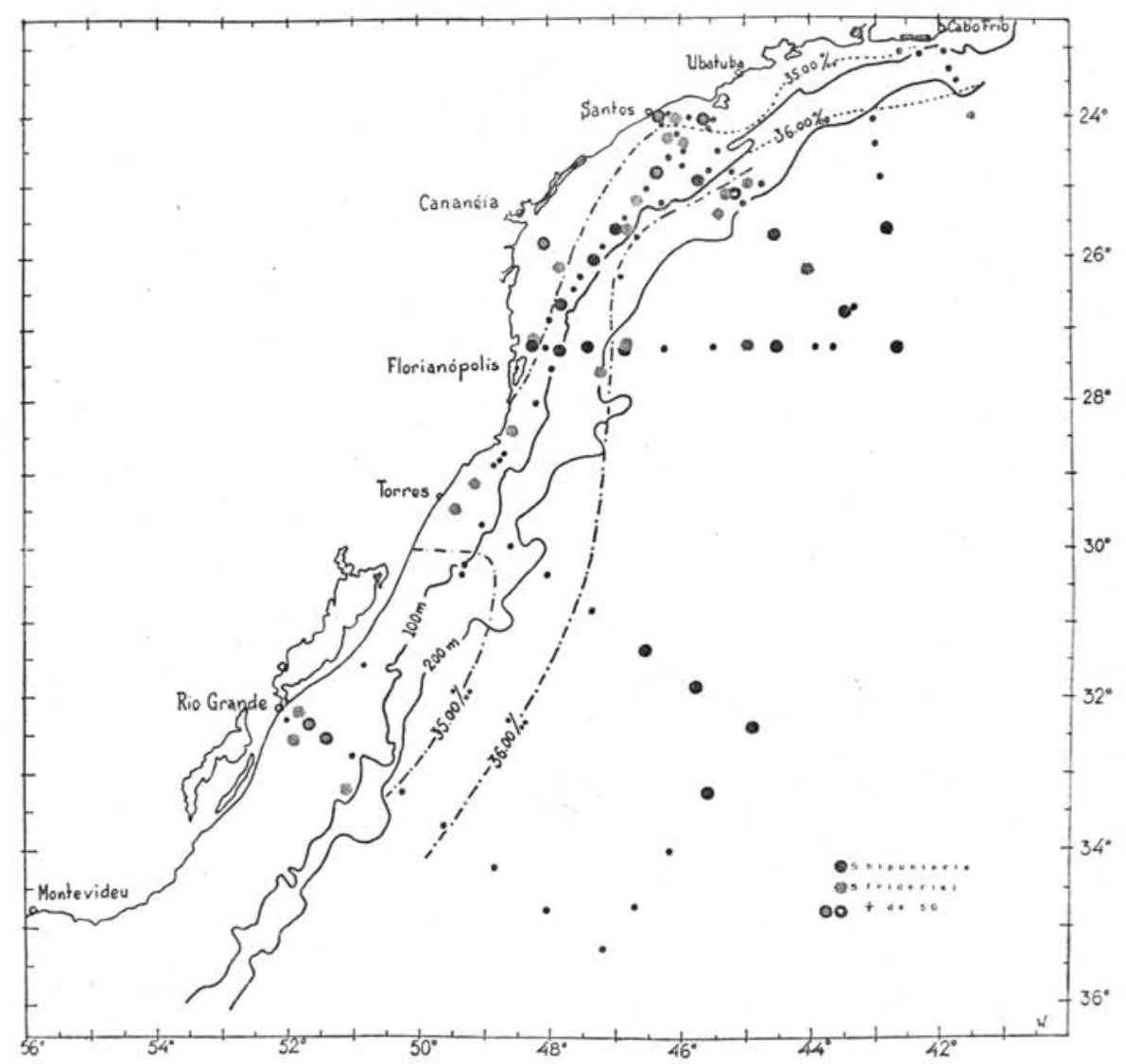

Fig. 2 - Mapa da distribuição de Sagitta bipunctata e S. friderici.

......... Iso-halinas de $35 \%$ e $36 \%$ em superfície medida durante as viagens feitas nos meses de fevereiro a março de 1956.

-.-.-.-.-. Iso-halinas de $35 \%$ e $36 \%$ em superfície medida durante as viagens feitas no mês de novembro.

águas de salinidade superior a 36,00\% igual a da Corrente da Flórida. Confirmamos sua esteno-halinidade e verificamos ser além disso euritérmica.

Sagitta enflata (Figs. 3 e 4) - Foi a espécie mais freqüente e abundante em nossas amostras. Embora presente em águas costeiras, da plataforma e tropical, ocorre com muito maior abundância em 
águas da plataforma (35 a 36,00\%). S. enflata parece suportar grande variação de temperatura e ocorre em águas de $18^{\circ} \mathrm{C}$ até $27^{\circ} \mathrm{C}$. Revelou, entretanto, uma marcada preferência por águas de $18^{\circ} \mathrm{C}$ a $21^{\circ} \mathrm{C}$. $S$. enflata foi muito mais numerosa em amostras coletadas sôbre a plataforma (até $200 \mathrm{~m}$ ). Comparando a ocorrência desta espécie com as medusas, podemos associar a presença de $S$. enflata com a de Liriope tetraphylla. S. enflata foi coletada desde $23^{\circ} 04^{\prime}$ S até $33^{\circ} 18^{\prime} \mathrm{S}$. A sua distribuição anual parece ser homogênea.

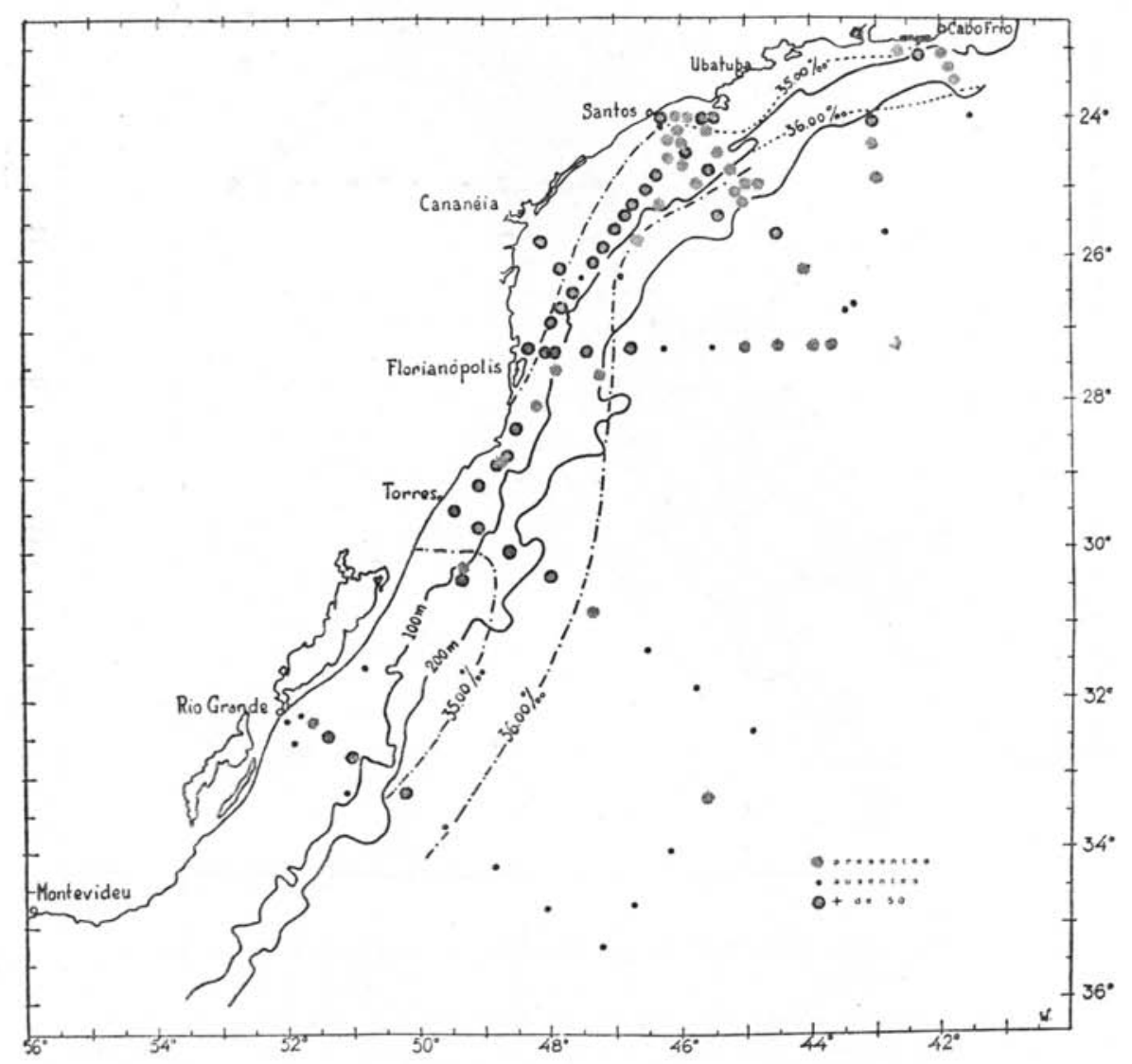

Fig. 3 - Mapa da distribuição de Sagitta enflata.

Discussão - Esta espécie já foi assinalada nesta região pela "Meteor" e "Liguria", mais ao norte por Vannucci \& Hosoe (1952, p. 12) na Ilha da Trindade e no Banco Jaseur e, finalmente, por Hosoe (1955, p. 2) em Fernando de Noronha. Parece não haver dúvida que esta é uma espécie de águas quentes, tanto nerítica 
quanto oceânica, típica de águas superficiais. Espécie amplamente euritérmica e euri-halina.

Sagitta friderici (Figs. 2 e 5) - Não foi muito freqüente neste material, provàvelmente, porque as coletas foram realizadas muito mais em águas da plataforma e tropical. Parece que esta espécie

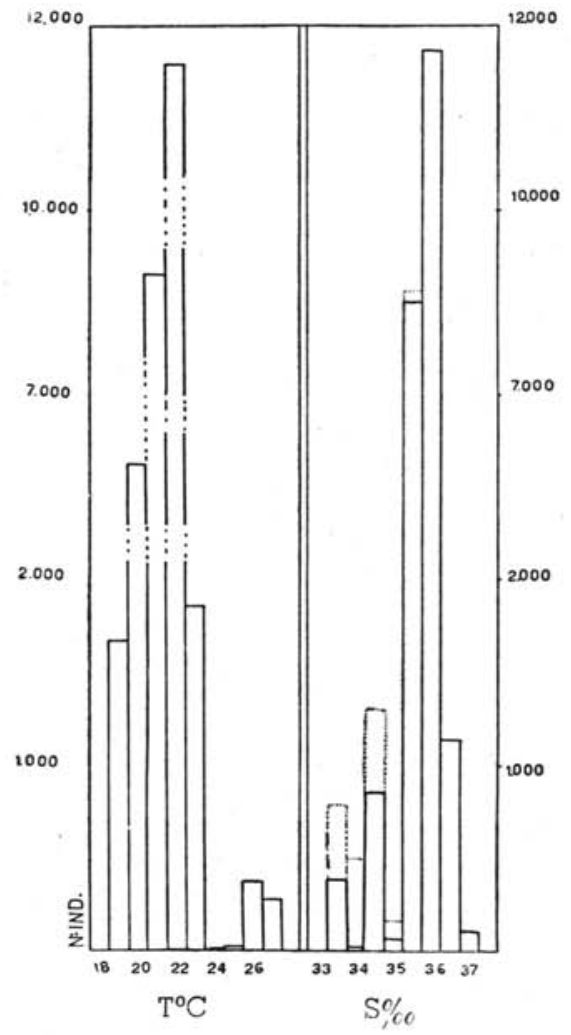

Fig. 4-Sagitta enflata. Gráfico da frequência de individuos em relação à salinidade e temperatura.

prefere concentrações baixas suportanco grande variação de salinidade. As amostras mais abundantes em $S$. friderici foram de águas costeiras; alguns exemplares, entretanto, foram coletados em águas da plataforma e tropical. As nossas amostras indicam, para essa espécie, uma euritermia acentuada, embora a maioria dos indivíduos tenham sido coletados a $21^{\circ} \mathrm{C}$. Os exemplares de S. friderici ocorreram em amostras coletadas desde $23^{\circ} 04^{\prime} \mathrm{S}$ até $32^{\circ} 36^{\prime} \mathrm{S}$. Não há evidência de variação nas diferentes épocas do ano.

Discussão - Sagitta friderici já foi assinalada no Atlântico Sul Ocidental por Thiel (1938, p. 29) e por Vannucci \& Hosoe 
(1952, p. 14) no Banco Jaseur e Ilha da Trindade. Segundo Furnestin (1952, p. 36) esta espécie é nerítica e de águas de baixa salinidade, mas, há dados que indicam que $S$. friderici pode suporter até $37,00 \%$ de salinidade (Vannucci \& Hosoe, l.c.). Furnestin

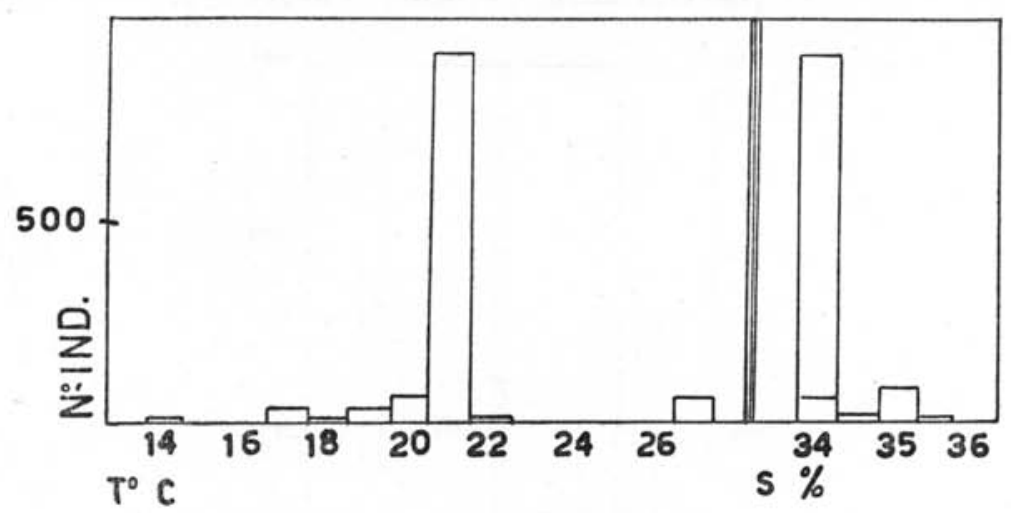

Fig. 5-Sagitta friderici. Gráfico da frequência de indivíduos em relação à salinidade e temperatura.

(1952, p. 35) indica limites de temperatura: de 14,5 a $19^{\circ} \mathrm{C}$ enquanto que em nossas águas coletamos exemplares de $S$. friderici em águas de até $27^{\circ} \mathrm{C}$.

Sagitta gloriae (Almeida Prado, 1960) (Fig. 6) - Dentre todos os Chaetognatha por nós coletados até agora esta é a única espécie nova. Analisando o conjunto das amostras verificamos que $S$. gloriae, foi pouco freqüente e pouco abundante com exceção da amostra $M_{93}$ de águas da plataforma em que foi pescado um cardume. Em muitas das amostras, esta espécie ocorreu junto com $S$. hexaptera, o que sugere que ela seja, provàvelmente, de profundidade. Os exemplares desta espécie ocorreram em águas da plataforma e tropical, e sòmente dois exemplares em águas costeiras. Quanto à temperatura parece suportar grande variação; coletamos S. gloriae em águas de 19 a $26^{\circ} \mathrm{C}$, sendo que na amostra $\mathrm{M}_{93}$ de águas com 25 a $26^{\circ} \mathrm{C}$, encontramos um número de indivíduos muito maior que nas demais. É interessante notar que nesta mesma amostra ocorreu também um cardume de $S$. hexaptera. Analisando o mapa de distribuição de $S$. gloriae, verificamos a presença de cardumes e isto é bem nítido nas amostras $\mathrm{M}_{142},{ }_{143}$, 144,145 .

Sagitta hexaptera (Fig. 6) - Como era de se esperar, esta espécie compareceu raramente e sempre em pequenas quantidades em nossas coletas, pois, estas foram feitas em camadas superficiais. A maioria dos indivíduos coletados são jovens, o que confirma Ho- 
soe $(1956$, p. 5), que também só encontrou formas jovens em superfície. As amostras que contêm maior número de $S$. hexaptera foram tomadas entre 1200 e $1400 \mathrm{~h}$. Os espécimes de $S$. hexaptera foram encontrados em uma única amostra de águas costeiras e, principalmente, em águas da plataforma e tropical. Comparece-

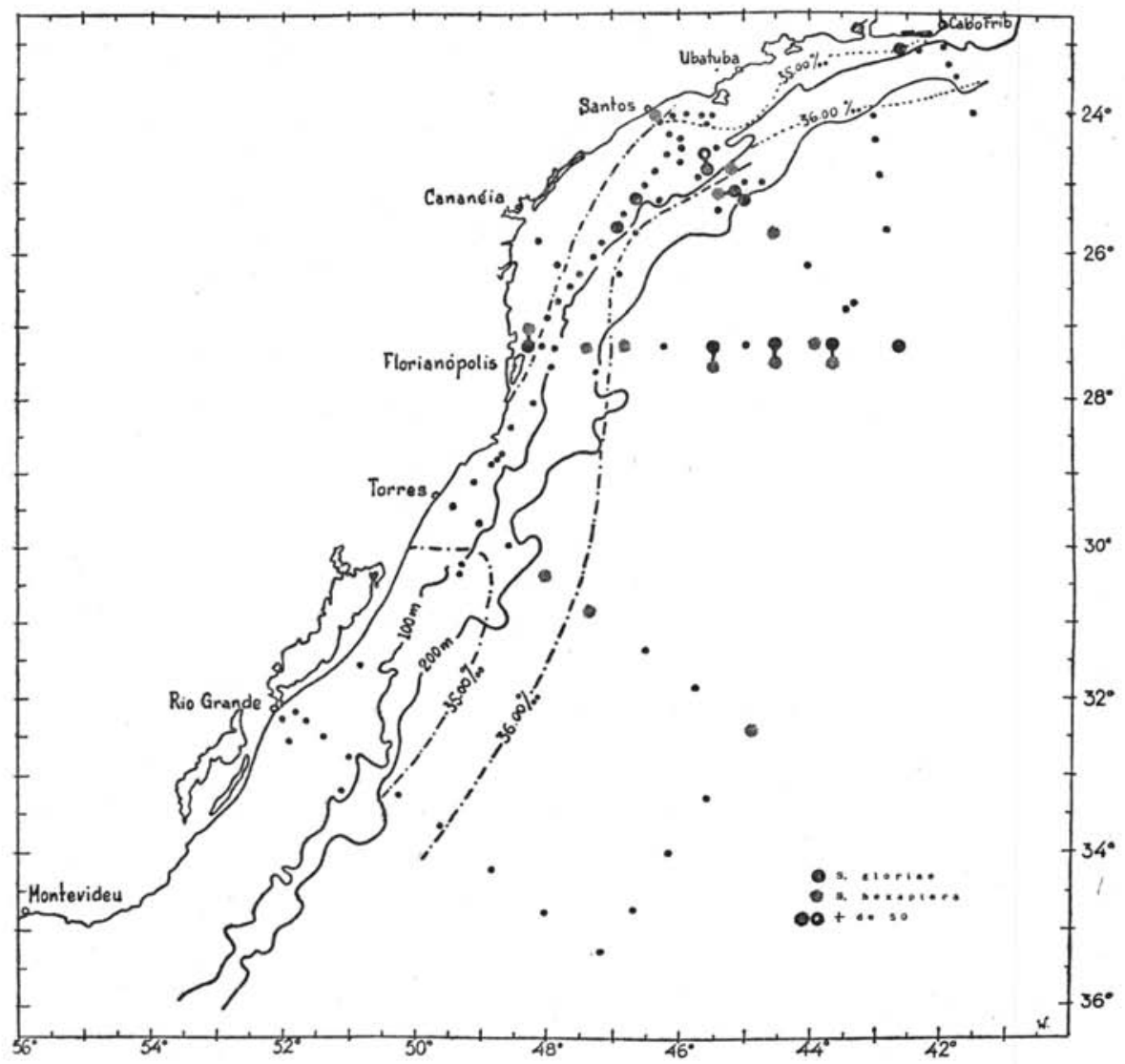

Fig. 6 - Mapa de distribuição de Sagitta gloriae e S. hexaptera.

ram em águas de salinidade desde 33,35 até $36,92 \%$. Esta espécie parece suportar grande variação de temperatura. Em nossas coletas, foi pescado em águas de 18 a $26^{\circ} \mathrm{C}$ sendo que em águas de 25 a $26^{\circ} \mathrm{C}$ foi encontrado um cardume. Os indivíduos são, provàvelmente, as formas jovens de uma população que migrou de camadas mais profundas para a superfície. No conjunto, as coletas parecem ter sido realizadas em águas onde estavam presentes pequenos car- 
dumes da espécie. Os exemplares foram coletados entre $23^{\circ} 04^{\prime} \mathrm{S}$ e $32^{\circ} 24^{\prime} \mathrm{S}$.

Discussão - A espécie já foi assinalada nesta região por Thiel (1938, p. 23), por Baldasseroni $(1915$, p. 89$)$, mais ao norte por Vannucci \& Hosoe $(1952$, p. 17) e finalmente por Hosoe $(1956$, p. 5), em Fernando de Noronha. Parece não haver dúvida que esta espécie seja característica de camadas mais profundas, que seja oceânica e raramente nerítica (Vannucci \& Hosoe 1952, p. 17). Os dados que encontramos na literatura, indicam que esta espécie suporta grande variação de temperatura. Fowler (1906, p. 78) assinala como mínimo $6^{\circ} \mathrm{C}$ e máximo $29^{\circ} \mathrm{C}$. Quanto à salinidade, parece ser mais exigente, segundo Furnestin (1957, p. 211) S. hexaptera vive em águas de salinidade superior a 36,30 até $36,64 \%$, entretanto, em latitudes mais setentrionais pode suportar salinidades inferiores a $35,00 \%$.

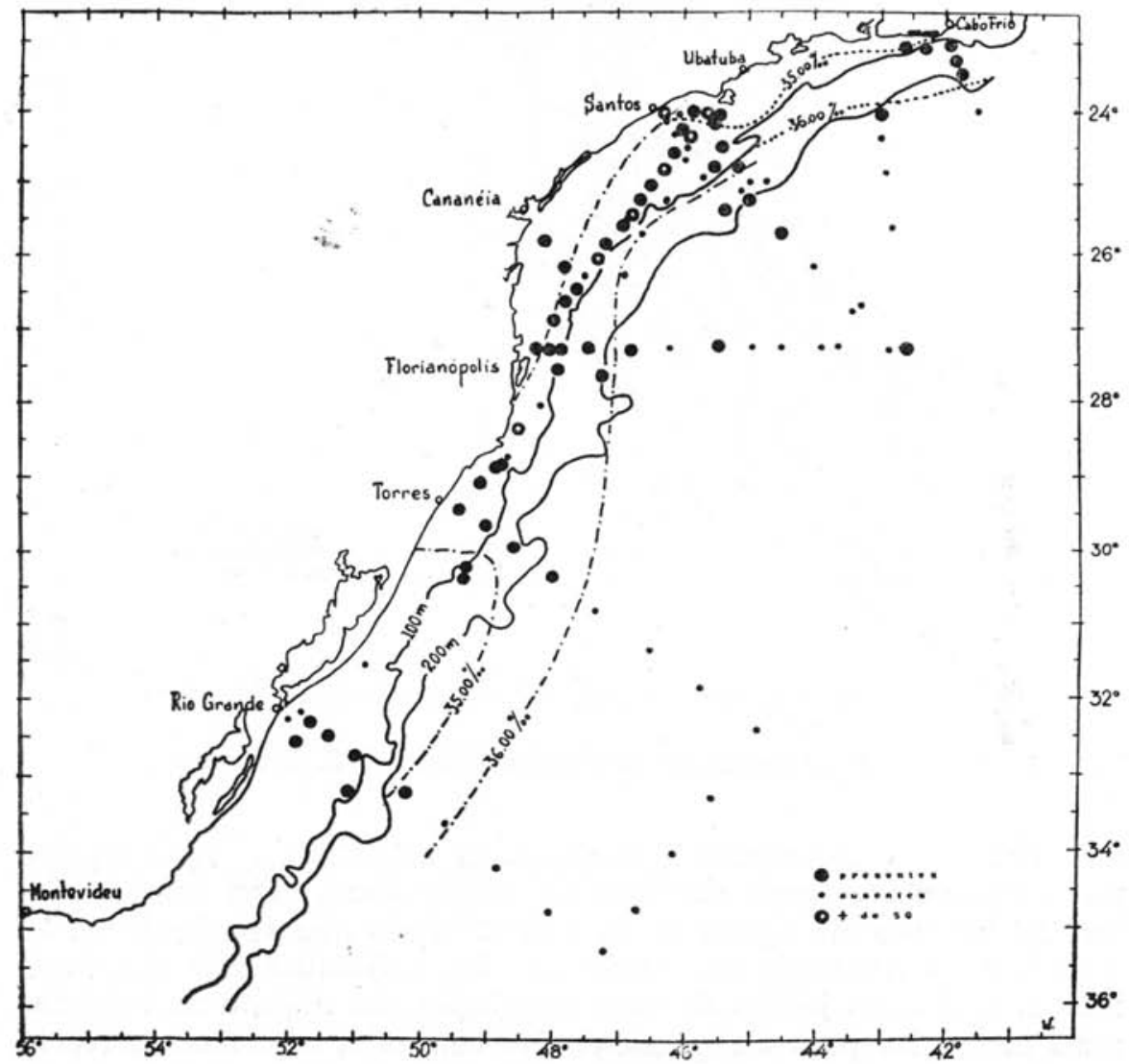

Fig. 7 - Mapa de distribuição de Sagitta hispida. 
Sagitta hispida (Figs. 7 e 8) - Foi relativamente abundante neste material, demonstrando acentuada preferência por águas da plataforma $(35,00$ a $36,00 \%$ de salinidade). Parece suportar grande variação de salinidade, pois, ocorreu também em águas costeiras (diluidas até $31,78 \%$ ) e tropical (até $36,99 \%$ ). Com relação a temperatura, também suporta uma grande variação. Foram encontrados exemplares em águas de 14 a $27^{\circ} \mathrm{C}$, embora, a maioria tenha sido coletada em águas de 19 a $22^{\circ} \mathrm{C}$. Sagitta hispida assim como $S$. enflata e $S$. minima estiveram presentes quase sempre sôbre a plataforma, atingindo algumas vêzes o talude. Encontramos $S$. hispida em águas da plataforma associada a Corymorpha gracilis e Proboscidactyla ornata. Os exemplares desta espécie foram coletados desde $23^{\circ} 04^{\prime} \mathrm{S}$ até $33^{\circ} 18^{\prime} \mathrm{S}$. Nas águas da plataforma, encontramos a mesma abundância, em junho e novembro.

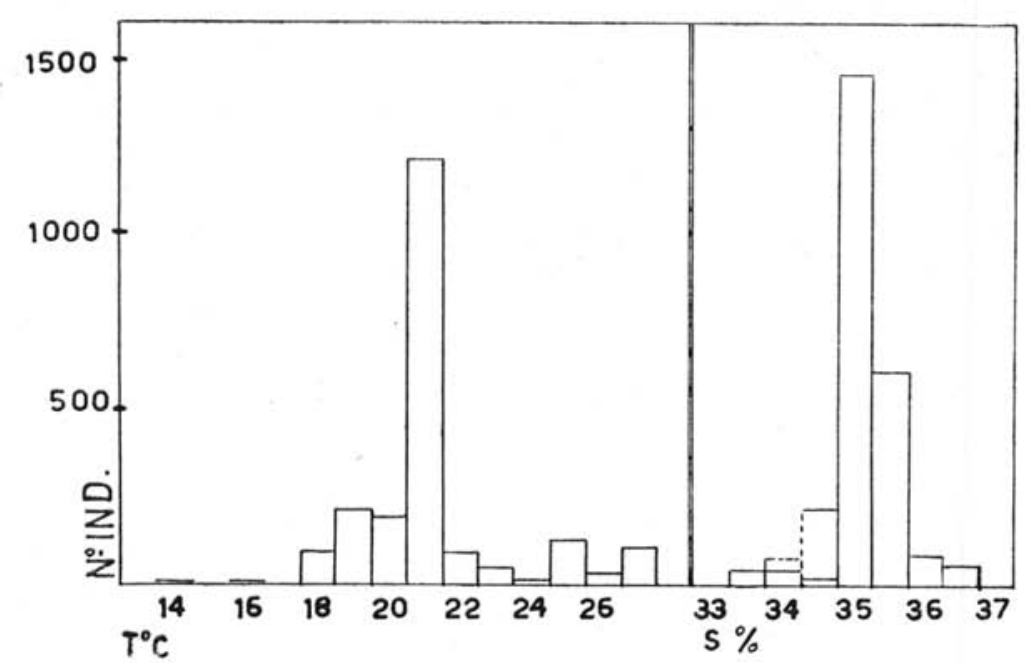

Fig. 8 - Sagitta hispida. Gráfico da frequência de indivíduos em relação à salinidade e temperatura.

Discussão - Não existe na literatura muita referência a respeito de $S$. hispida, talvez porque ela tenha sido muitas vêzes confundida com S. robusta (Almeida Prado 1961, p. 36-37). Esta espécie é agora encontrada pela primeira vez nesta área, porém, Thiel (1938, p. 32) assinalou S. robusta nesta mesma região. Segundo Furnestin (1960, p. 149), S. hispida é forma nerítica e epiplanctônica, típica das águas costeiras senegalenses, com salinidade inferior a $36,00 \%$. Bumpus \& Pierce $(1955$, p. 105), encontraram esta espécie em águas costeiras com salinidade de $31-35,00 \%$. 
Sagitta minima (Figs. 9 e 10) - Foi coletada, principalmente, em águas da plataforma, com salinidade de $35,00 \%$ e mais raramente em água tropical, de salinidade superior a 36,00\%. Excepcionalmente, encontramos em águas de salinidade inferior a $35.00 \%$, alguns exemplares de $S$. minima, mas infelizmente as coletas foram verticais e atravessaram várias massas de água de diferentes salinidades. Não podemos, portanto, ter a certeza de que os indivíduos se encontravam em águas costeiras. $S$. minima se mostrou exigente com relação a temperatura, demonstrando suportar um limite de variação muito mais restrito do que o das demais espécies. Em temperaturas inferiores a $18^{\circ} \mathrm{C}$ e superiores a $21^{\circ} \mathrm{C}$, a espécie desaparece quase que completamente. As coletas verticais realizadas em águas de temperatura inferior a $18^{\circ} \mathrm{C}$, que continham $S$. minima, atravessaram uma coluna de água com grande variação de tempe-

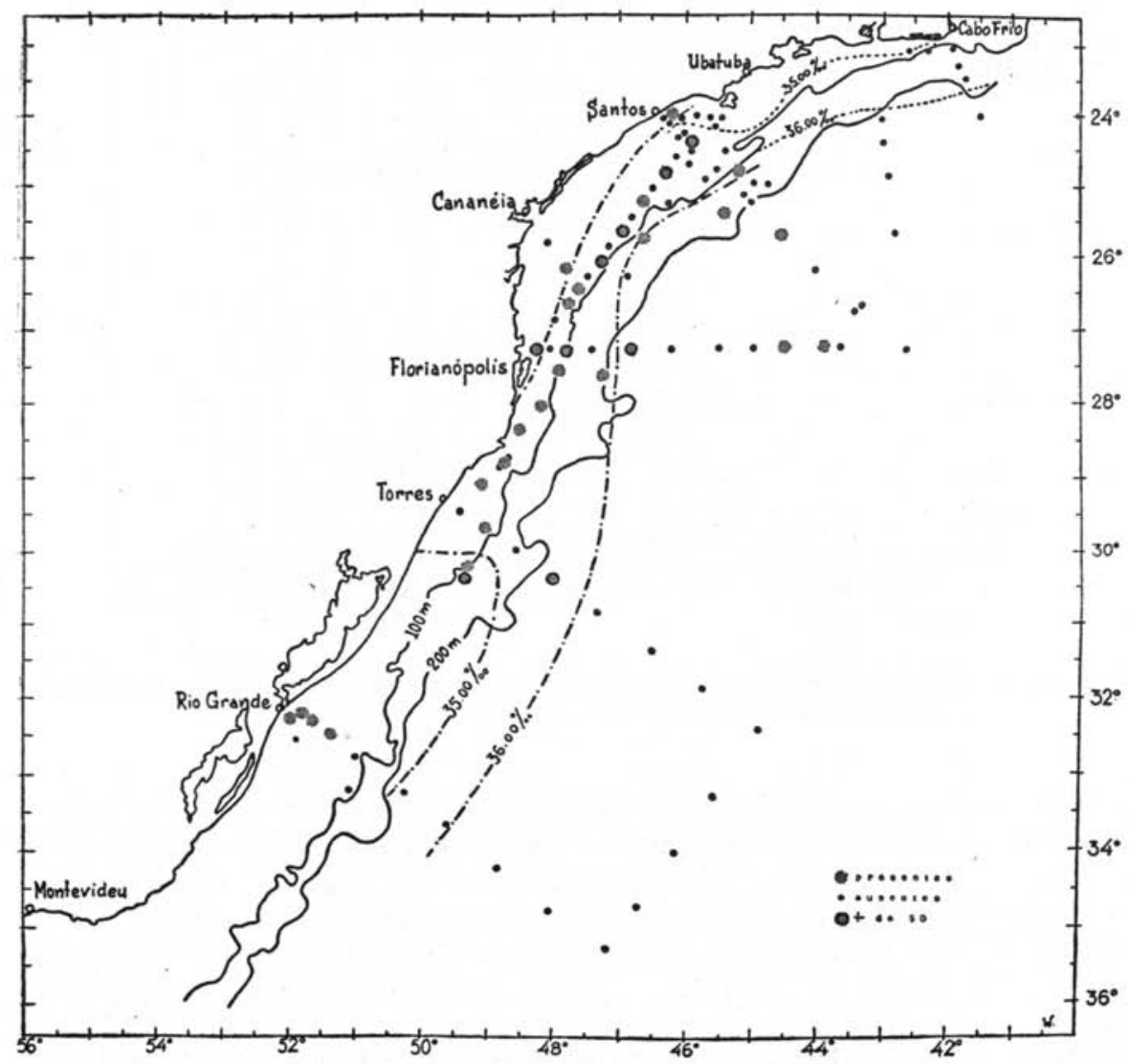

Fig. 9 - Mapa de distribuição de Sagitta minima. 
ratura, de modo que não pudemos precisar exatamente a que temperatura se encontrava a massa de água em que êsses exemplares foram coletados. Esta espécie foi, dentre tôdas as demais dêste material, a que apresentou limites de temperatura e salinidade melhor definidos. Os exemplares de S. minima foram coletados desde $24^{\circ} 04^{\prime} \mathrm{S}$ até $32^{\circ} 30^{\prime} \mathrm{S}$, sendo que as amostras mais abundantes nesta espécie foram tomadas entre Santos e Florianópolis. Nas amostras de água da plataforma, S. minima foi mais abundante em junho.

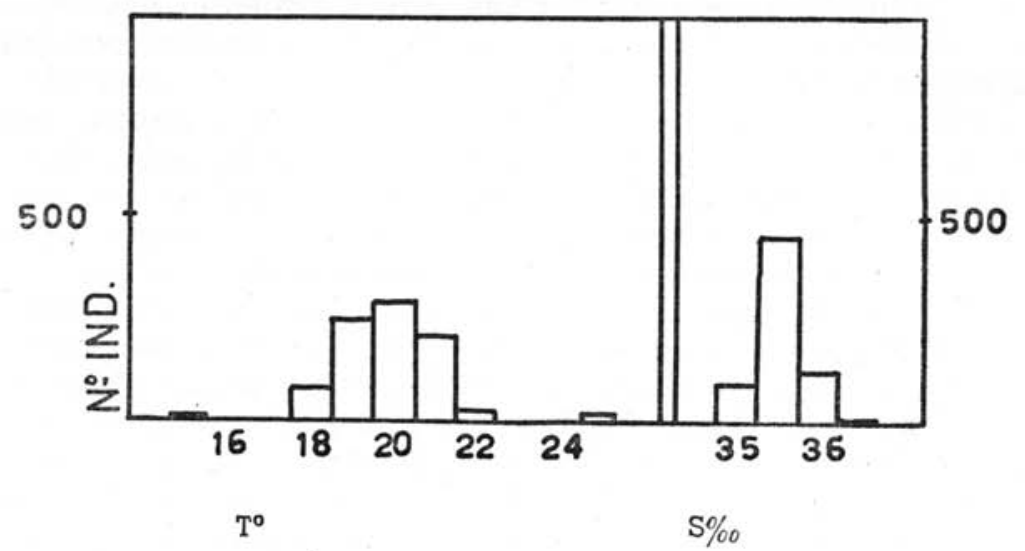

Fig. 10 - Sagitta minima. Gráfico da frequência de indivíduos em relalação à salinidade e temperatura.

Discussão - S. minima já foi coletada, pela "Meteor" (Thiel 1938, p. 39), entre Florianópolis e a latitude de Montevideu. Os nossos dados ecológicos encontrados para S. minima, em geral concordam com os dados da literatura. A espécie é epiplanctônica, segundo Fowler $(1906$, p. 71$)$, e mesoplanctônica, segundo Furnestin $(1957$, p. 198). Guaita $(1958$, p. 52) considera-a tanto oceânica como nerítica e Furnestin (1957, p. 195), nerítica com tendência a oceânica. Thiel (1938, p. 40) encontrou S. minima em águas de 15 a $20^{\circ} \mathrm{C}$; Fowler $(1906$, p. 71$)$ em águas de 19 a $21^{\circ} \mathrm{C}$ no Pacífico e Guaita (1958, p. 52), em águas do Chile de 11,6 a $22^{\circ} \mathrm{C}$. Os limites de salinidade em que ocorre esta espécie são também concordantes. Furnestin (1957, p. 199) assinala-a em águas de salinidade superior a $36,00 \%$ e Bumpus \& Pierce $(1955$, p. 106) encontraram-na em águas de $36,00 \%$ de salinidade.

Sagitta serratodentata (Figs. 11 e 12) - Foi das espécies mais freqüentes e abundantes em nosso material. Os exemplares foram coletados em águas do norte e da plataforma. Entretanto, é nítida a preferência por águas de salinidade superior a 36,00\%. Excepcionalmente, foi coletada $S$. serratodentata em águas de salinidade de $33,00 \%$. No entretanto, êste dado é considerado duvidoso porque 
a rêde foi usada com $50 \mathrm{~m}$ de cabo, de modo que, é possível que tenha pescado em camadas inferiores de salinidade superior a $35,00 \%$. Na amostra $\mathrm{M}_{122}$, coletada em águas de salinidade baixa $(34,14-34,08 \%)$, encontramos $S$. serratodentata juntamente com outros organismos típicos de águas de alta salinidade. Êste fato pode ser explicado como provável migração dos indivíduos de camadas inferiores $(50 \mathrm{~m})$ de salinidade mais alta para a superfície, pois, a coleta foi feita as $2400 \mathrm{~h}$ (veja p. 18). Em relação à temperatura, esta espécie tem-se comportado diferentemente, pois, revelou suportar grande variação de temperatura. Encontramos exemplares em águas com temperatura desde 18 até $26^{\circ} \mathrm{C}$. S. serratodentata demonstrou ser amplamente euritérmica e esteno-halina, confirmando a sua preferência pela água tropical, pois, esta massa de água conserva a salinidade, mas perde a temperatura em direção ao sul. Um fato interessante nos chamou a atenção quando examinamos a ocorrência de $S$. serratodentata em água tropical. À medida que caminhamos para o sul, há uma crescente predominância dos exemplares desta espécie e simultaneamente, o decréscimo numérico das demais. Isto decorre provàvelmente, do empobrecimento da água tropical, fazendo com que sòmente uma espécie resistente atinja latitudes mais altas. S. serratodentata ocorreu desde $24^{\circ} 22^{\prime}$ S até $35^{\circ} 18^{\prime} \mathrm{S}$. Encontramos um grande número de exemplares nas amostras $M_{158}$ a $M_{164}$, talvez porque estas coletas atingiram camadas mais profundas. Concluindo, podemos confirmar Vannucci \& Hosoe (1952, p. 19-29): a espécie é esteno-halina não muito estrita e amplamente euritérmica. Analisando a quantidade de indivíduos em cada coleta verificamos a presença de cardumes de $S$. serratodentata.

Relacionando a presença de certas medusas (Vannucci, 1957) e S. serratodentata, pudemos caracterizar as diferentes massas de água pelas seguintes associações:

1 - Aguas tropicais - S. serratodentata, Aglaura hemistoma e em menor número $S$. hispida, Liriope tetraphylla e Solmundella bitentaculata; Aegina citrea, embora seja uma espécie rara, ocorreu sempre junto com S. serratodentata em águas tropicais. Pterosagitta draco também é uma espécie típica da água tropical, porém, nas latitudes aqui estudadas é muito mais rara do que $S$. serratodentata. Germain \& Joubin (1916, p. 6) encontraram S. bipunctata associada a $S$. serratodentata e esta mesma associação foi verificada por nós na água tropical.

2 - Agua da plataforma - S. hispida e Liriope tetraphylla predominando sôbre $S$. serratodentata e Aglaura hemistoma.

Discussão - S. serratodentata já foi assinalada nesta região por vários autores: Baldasseroni $(1915$, p. 89$)$ e Thiel $(1938$, p. 16) registraram-na nas costas de Santa Catarina e do Rio Grande do Sul, Burfield (1930, p. 223) coletou-a entre $25^{\circ}$ e $15^{\circ} \mathrm{S}$, Vannucci 
\& Hosoe (1952, p. 19) no Banco Jaseur e na Ilha da Trindade e por Hosoe (1956, p. 1) em Fernando de Noronha. Segundo a maioria dos autores, $S$. serratodentata é uma forma típica de superfície que pode atingir camadas mais profundas. Germain \& Joubin $(1916$, p. 1) assinalam a presença desta espécie em grandes profundidades. Entretanto, êstes autores usaram rêde aberta e sem-

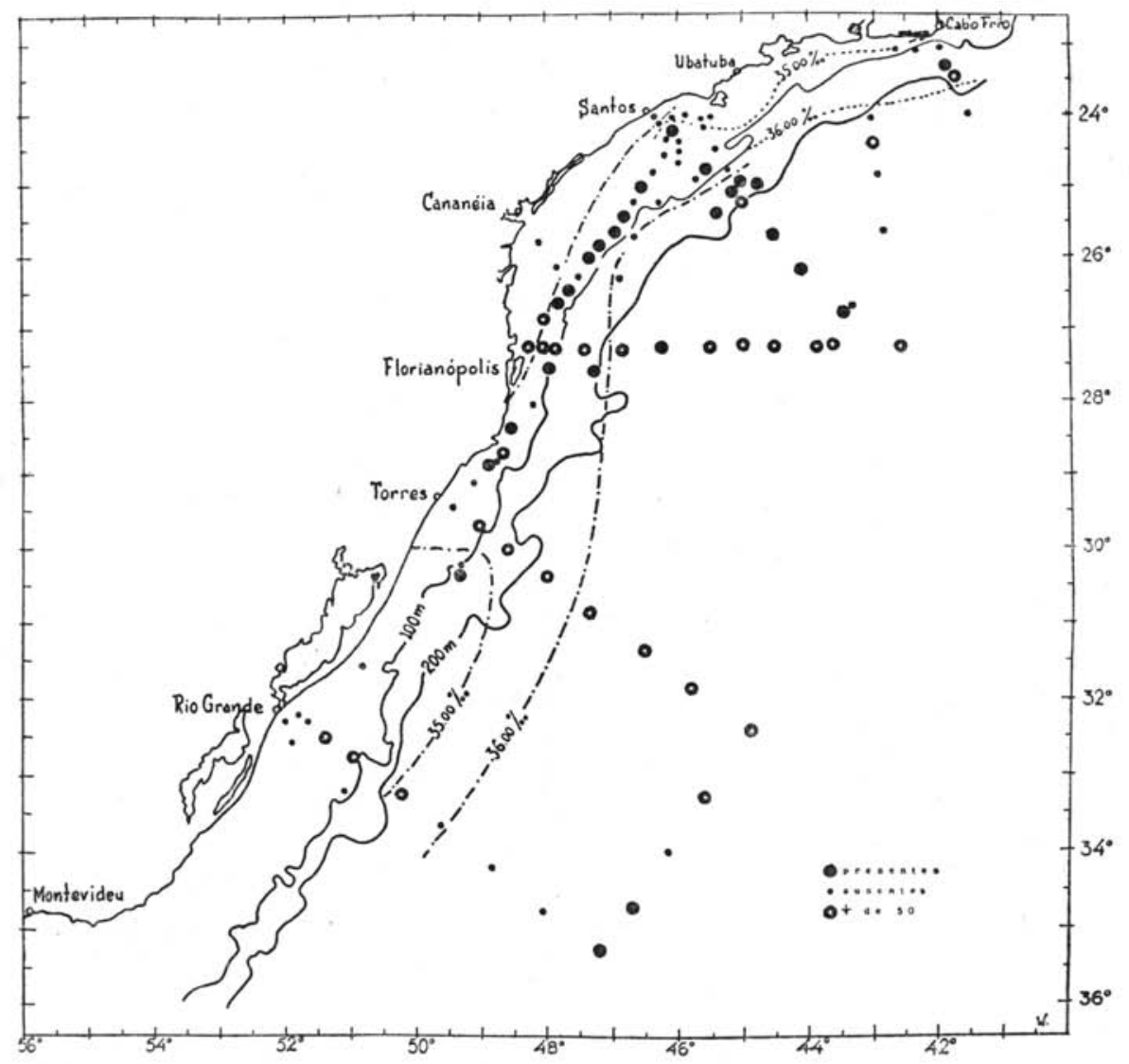

Fig. 11 - Mapa da distribuição de Sagitta serratodentata.

pre resta a possibilidade dos exemplares terem sido colhidos na superfície (Vannucci \& Hosoe 1952, p. 19). Os dados de salinidade em que é encontrada a espécie são, na maioria das vêzes, concordantes. Parece ser indiscutível que ela exige alta salinidade. Segundo Vannucci \& Hosoe (1952, p. 20), a espécie desaparece quando transportada para águas de salinidade inferior a $35,00 \%$, o que de certo modo, é confirmado pelo presente material. Hosoe (1956, 
p. 1), verificou em águas de salinidade superior a $36,00 \%$ (Fernando de Noronha), que $S$. serratodentata era a espécie mais abundante. Pierce (1953, p. 89) também encontrou esta espécie relacionada com águas de $36,00 \%$ de salinidade. Guaita (1958, p. 43)

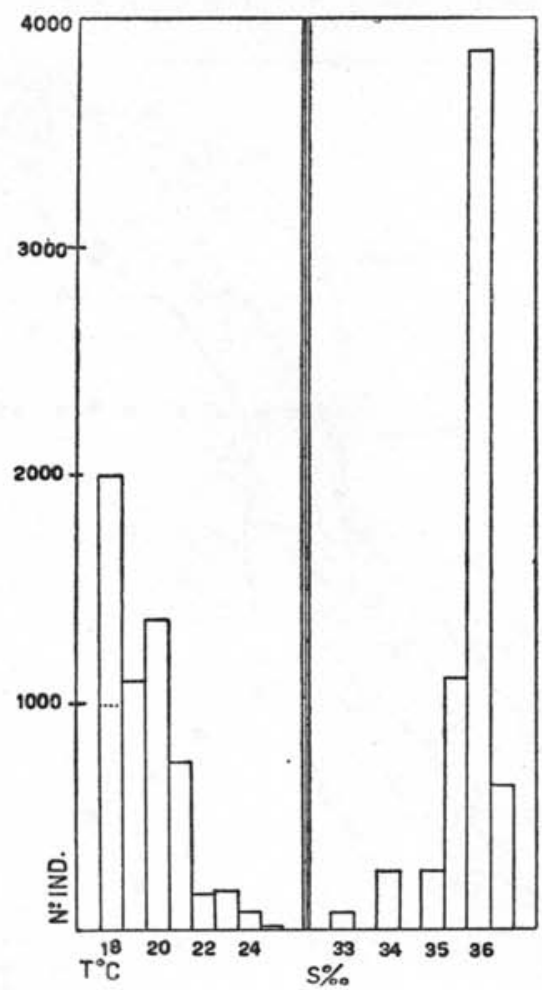

Fig. 12 - Sagitta serratodentata. Gráfico da frequência de indivíduos em relação à salinidade e temperatura.

considera-a espécie de alta salinidade. Os dados relativos à temperatura são mais contraditórios: a espécie parece ser amplamente euritérmica. Segundo Fraser (1952, p. 15), S. serratodentata suporta temperatura muito baixa, até mesmo $0^{\circ} \mathrm{C}$. Ela é considerada, pela maioria dos autores, uma espécie oceânica.

Pterosagitta draco (Fig. 13) - Não é nem muito freqüente, nem muito abundante neste material. Foi coletada principalmente na água tropical $(36-37,00 \%)$ e mais raramente em águas da plataforma $(35-36,00 \%)$. Sòmente em duas estações de àguas costeiras $\mathrm{M}_{122}$ e $\mathrm{M}_{173}$ foram encontrados alguns exemplares desta espécie, aliás, juntamente com outros Chaetognatha típicos de águas de alta sali- 
nidade. Como já se explicou anteriormente, os indivíduos encontrados nesta camada, devem ser provenientes, por migração vertical, de águas mais profundas e de salinidade superior a $35,00 \%$. Os exemplares de $P$. draco foram coletados em águas de 18 a $23^{\circ} \mathrm{C}$, sendo mais abundante entre 20 e $22^{\circ} \mathrm{C}$. Embora esta espécie tenha sido encontrada sempre associada a $S$. serratodentata, não ocorreu com a mesma freqüência. Ao contrário de $S$. serratodentata, ela diminuiu nas amostras tomadas mais ao sul. Pterosagitta draco foi encontrada desde $24^{\circ} 01^{\prime} \mathrm{S}$ até $34^{\circ} 42^{\prime} \mathrm{S}$, porém, foi mais freqüente e abundante nas coletas tomadas na latitude de Florianopólis.

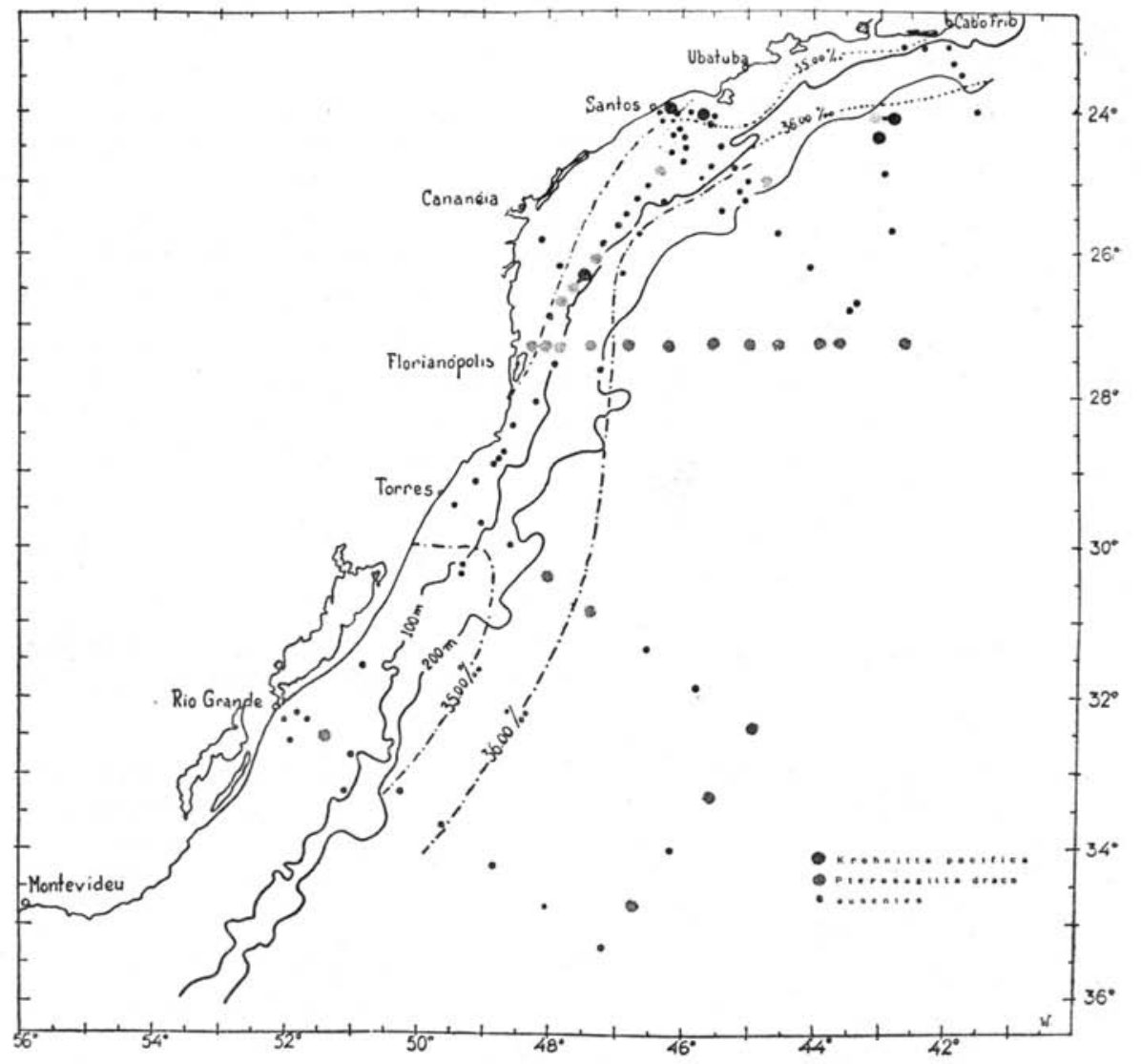

Fig. 13 - Mapa da distribuição de Pterosagitta draco e Krohnitta pacifica.

Discussão - $P$. draco já foi registrada no Atlântico Sul Ocidental por Baldasseroni (1915, p. 89) entre Santa Catarina e Rio Grande do Sul, por Thiel (1938, p. 55) entre Bahia e Buenos Aires 
e por Hosoe (1956, p. 3) em Fernando de Noronha. Vannucci \& Hosoe $(1952$, p. 20) mencionaram-na como P. besnardi. Nossas coletas indicam que a espécie é oceânica, fato êste confirmado por outros autores, em outras regiões. Pierce (1953, p. 87), Furnestin (1957, p. 253) e Guaita (1958, p. 66) também consideram-na uma espécie de alto mar. $P$. draco é freqüentemente assinalada como espécie típica de águas quentes e de alta salinidade. Furnestin (1957, p. 254), Pierce $(1953$, p. 89$)$ e Hosoe $(1956$, p. 3) assinalam-na em águas de salinidade superior a $36,00 \%$. Suporta uma variação de temperatura bem mais ampla que a salinidade. Fowler (1906, p. 78) encontrou-a em águas de 17 a $29^{\circ} \mathrm{C}$; Hosoe (l.c.) em águas de temperatura superior, de 27 até $29^{\circ} \mathrm{C}$. Há indícios de que ela não seja exclusivamente epiplanctônica.

Krohnitta pacifica (Fig. 13) - É a espécie mais rara dêste material. Foi coletada apenas em quatro estações, cujas amostras mais abundantes são provenientes de águas costeiras e de plataforma. Sòmente quatro exemplares foram encontrados em água tropical. K. pacifica estêve presente em amostras provenientes de coletas superficiais, no máximo até $10 \mathrm{~m}$, em águas com 19 a $24^{\circ} \mathrm{C}$.

Discussão - Hosoe (1956, p. 4) assinala, como nós, a presença de $K$. pacifica em Fernando de Noronha em águas de alta salinidade e temperatura. Pierce $(1955$, p. 107) encontrou K. pacifica associada à Corrente da Flórida em águas de salinidade superior a $36,00 \%$.

\section{CONCLUSÕES GERAIS}

Tendo em vista o presente material e os dados fornecidos pela literatura podemos apresentar, agora, resumidamente, as conclusões gerais dêste trabalho.

Encontramos um grande número de formas muito jovens que não pudemos classificar. Analisando, entretanto, a ocorrência dessas formas jovens pudemos verificar a presença de cardumes. Êste fato é nítido como o demonstram os gráficos de porcentagem das espécies por amostras (Figs. 14, 15, 16).

Das 10 espécies coletadas, sòmente, Sagitta gloriae sp. n. e Krohnitta pacifica foram, pela primeira vez assinaladas nesta região.

Sagitta friderici é uma espécie costeira, mas pode ser encontrada em águas da plataforma. Não verificamos, por enquanto, nenhuma associação de Chaetognatha, característica desta água.

Sagitta enflata, Sagitta minima, Sagitta hispida são espécies predominantes em águas da plataforma, apesar de terem sido encontradas também em águas costeira e tropical. 


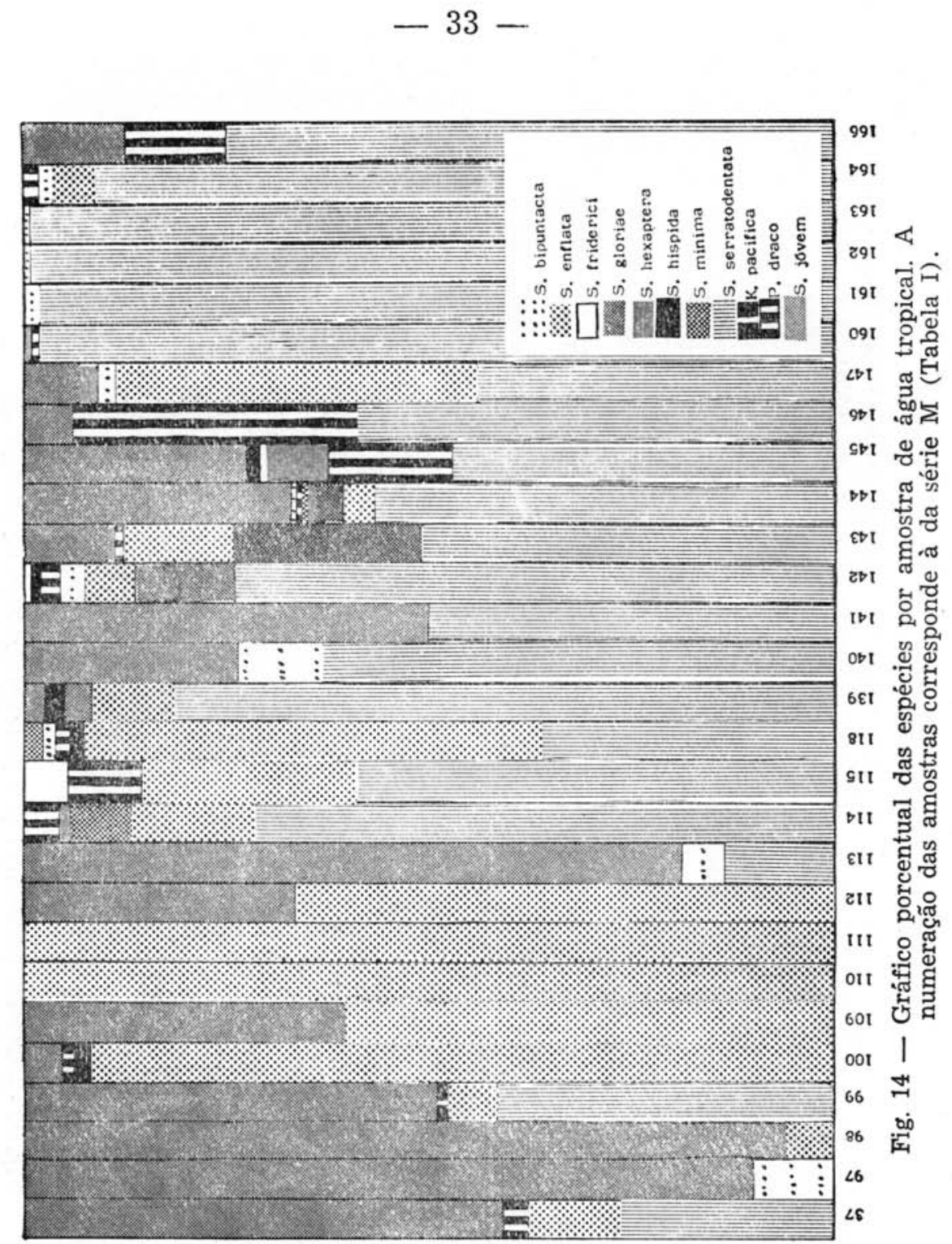

Sagitta serratodentata e Pterosagitta draco são espécies típicas de água tropical podendo ser encontradas com menor freqüência em águas da plataforma.

Sagitta hexaptera, Sagitta bipunctata e Sagitta gloriae foram sempre pouco freqüentes e estiveram presentes em águas da plataforma e tropical. 


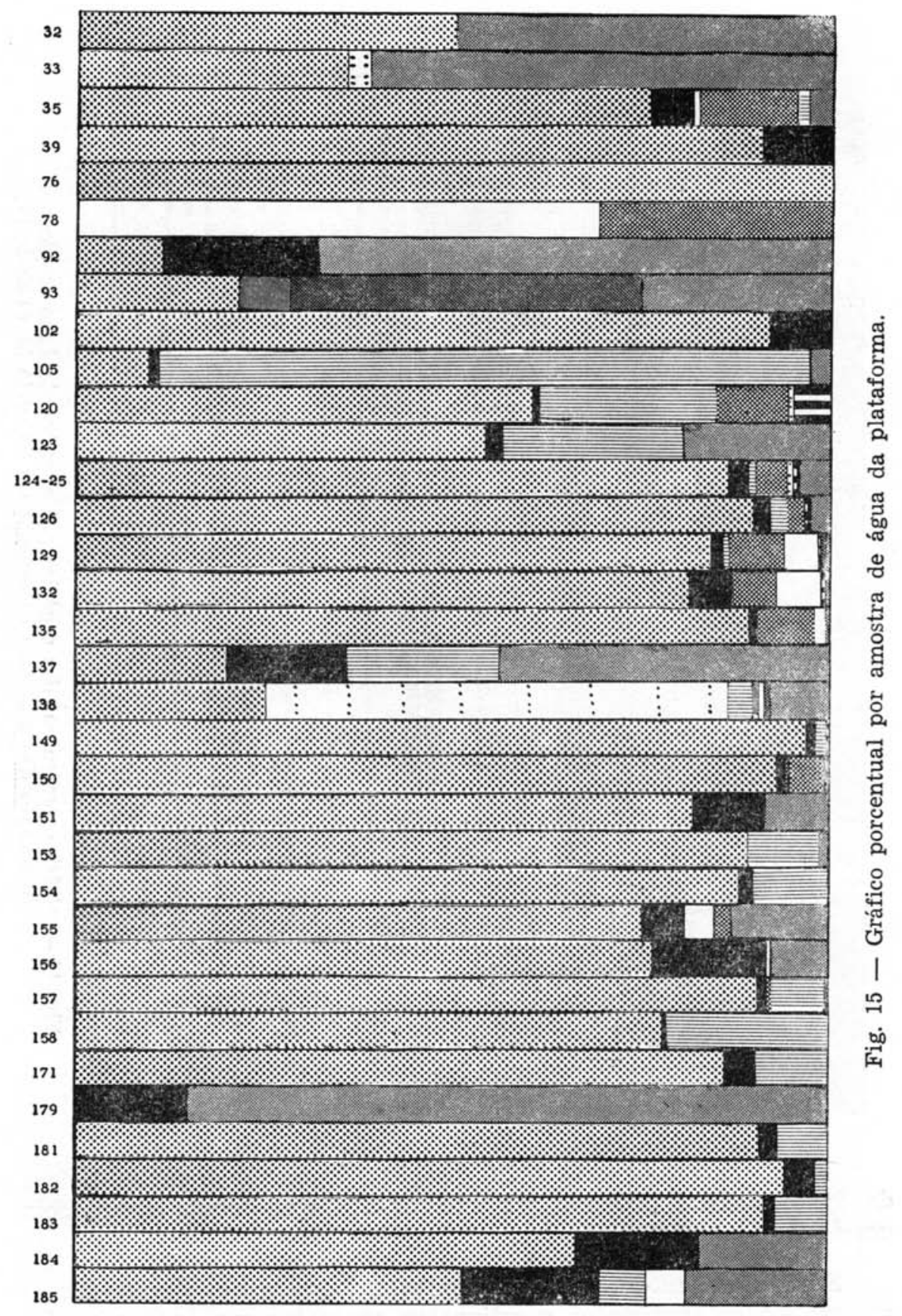


Krohnitta pacifica, representada por poucos indivíduos, foi encontrada indiferentemente nas 3 massas de água.

Relacionamos a ocorrência simultânea de certas espécies de Hydromedusae e de Chaetognatha com a massa de água.

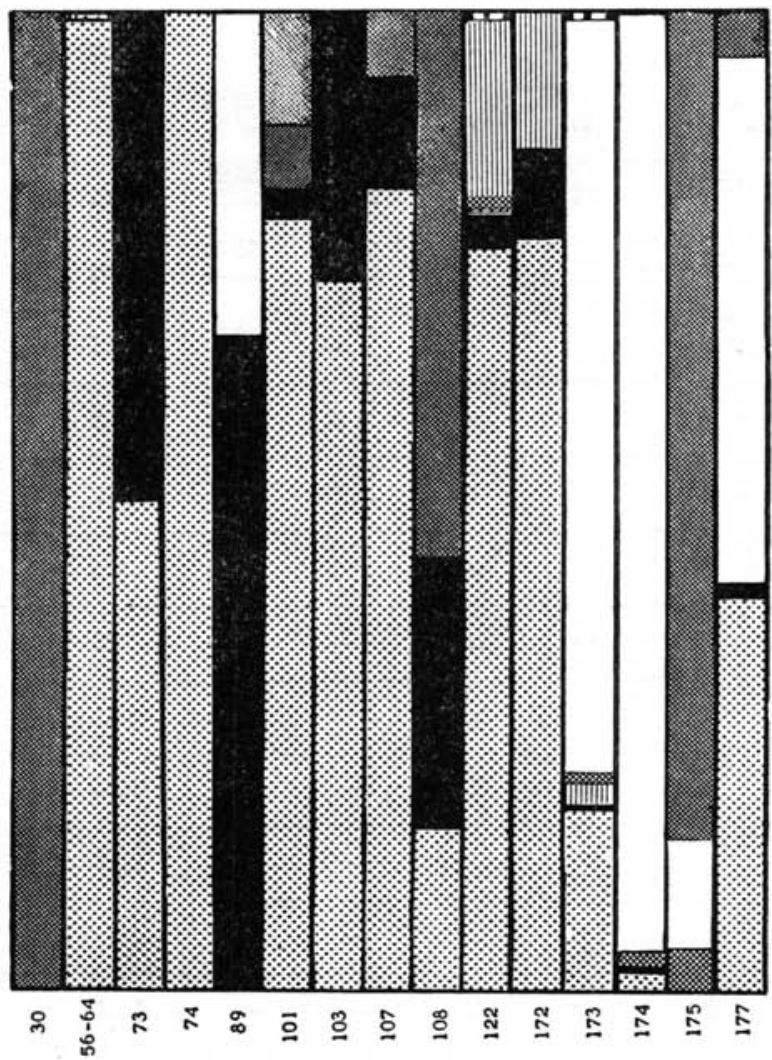

Fig. 16 - Gráfico porcentual das espécies por amostra de água costeira.

\section{RESUMO}

Estuda-se neste trabalho, a distribuição geográfica dos Chaetognatha no Atlântico Sul Ocidental relacionando as dez espécies encontradas com as diferentes massas de água. Foram feitas estações em águas costeira, da plataforma e tropical. Finalmente, foi relacionada a presença dos Chaetognatha e das medusas com as diferentes massas de água. 
TABELA I - LISTA DAS ESTAÇõES E NÚMERO DE INDIVÍDUOS,

\begin{tabular}{|c|c|c|c|c|c|c|c|c|c|}
\hline Amostra & Data & Posição & $\begin{array}{l}\text { Prof. } \\
\text { local } \\
\text { (m) }\end{array}$ & $\begin{array}{l}\text { Prof. da } \\
\text { coleta } \\
\text { (m) }\end{array}$ & Temp. & Salin. & Hora & $\begin{array}{l}\text { Duração } \\
\text { do lance } \\
\text { (min) }\end{array}$ & $\begin{array}{l}\text { Tipo } \\
\text { de rêdo }\end{array}$ \\
\hline $\begin{array}{l}\text { Est. 1 } \\
\text { M } 30 \\
\text { "Igaraty" }\end{array}$ & $26 / 6 / 54$ & $\begin{array}{l}24^{\circ} 06^{\prime} \mathrm{S} \\
46^{\circ} 14^{\prime} \mathrm{W}\end{array}$ & 14 & $12 \frac{\mathrm{V}}{\mathrm{U}}$ & $\begin{array}{l}21.70 \\
21.40\end{array}$ & $\begin{array}{l}33.48 \\
33.77\end{array}$ & 2300 & - & Standard \\
\hline $\begin{array}{l}\text { Est. } 2 \\
\text { M } 31 \\
\text { "Igaraty" }\end{array}$ & $27 / 6 / 54$ & $\begin{array}{l}24018^{\prime} \mathrm{S} \\
46006^{\prime} \mathrm{W}\end{array}$ & 39 & $12 \frac{\mathrm{V}}{\mathrm{V}}$ & $\begin{array}{l}21.4 U \\
21.60\end{array}$ & $\begin{array}{l}34.84 \\
35.27\end{array}$ & 0109 & - & Standard \\
\hline $\begin{array}{l}\text { Est. }{ }^{3} \\
\text { M } 32 \\
\text { "Igaraty }\end{array}$ & $27 / 6 / 54$ & $\begin{array}{l}24033^{\prime} \mathrm{S} \\
45^{\circ} 57^{\prime} \mathrm{W}\end{array}$ & 36 & ${ }^{12} \mathrm{v}^{0}$ & $\begin{array}{l}21.60 \\
21.40\end{array}$ & $\begin{array}{l}35.58 \\
35.61\end{array}$ & 0400 & - & Standard \\
\hline $\begin{array}{l}\text { Est. } 4 \\
\text { M } 33 \\
\text { "Igaraty" }\end{array}$ & $27 / 6 / 54$ & $\begin{array}{l}24057^{\prime} \mathrm{S} \\
45^{\circ} 42^{\prime} \mathrm{W}\end{array}$ & 73 & $12-0$ & $\begin{array}{l}21.60 \\
21.60\end{array}$ & $\begin{array}{l}35.81 \\
35.92\end{array}$ & 0815 & - & Standard \\
\hline $\begin{array}{l}\text { Est. } 5 \\
\text { M } 35 \\
\text { "Igaraty" }\end{array}$ & $27 / 6 / 54$ & $\begin{array}{l}25^{\circ} 26^{\prime} \mathrm{S} \\
45^{\circ} 25^{\prime} \mathrm{W}\end{array}$ & 106 & $48 \frac{\mathrm{V}}{0}$ & $\begin{array}{l}21.90 \\
16.90\end{array}$ & $\begin{array}{l}35.09 \\
35.54\end{array}$ & 1452 & - & Standard \\
\hline $\begin{array}{l}\text { Est. } 6 \\
\text { M } 36 \\
\text { "Igaraty" }\end{array}$ & $27 / 6 / 54$ & $\begin{array}{l}25009^{\prime} \mathrm{S} \\
44055^{\prime} \mathrm{W}\end{array}$ & 121 & $30 \frac{0}{\mathrm{~V}} 0$ & $\begin{array}{l}22.9 \% \\
22.90\end{array}$ & $\begin{array}{l}35.93 \\
36.40\end{array}$ & 2035 & - & Standard \\
\hline $\begin{array}{l}\text { Est. } 7 \\
\text { M } 37 \\
\text { "Igaraty" }\end{array}$ & $27 / 6 / 54$ & $\begin{array}{l}25002^{\prime} \mathrm{S} \\
44^{\circ} 42^{\prime} \mathrm{W}\end{array}$ & 136 & $30 \frac{v}{v}$ & $\begin{array}{l}23.30 \\
23.30\end{array}$ & $\begin{array}{l}36.40 \\
36.44\end{array}$ & 2355 & - & Standard \\
\hline $\begin{array}{l}\text { Est. } 8 \\
\text { M 38 } \\
\text { "Igaraty" }\end{array}$ & $28 / 6 / 54$ & $\begin{array}{l}24050^{\prime} \mathrm{S} \\
45012^{\prime} \mathrm{W}\end{array}$ & 82 & $30 \frac{\mathrm{v}}{0}$ & $\begin{array}{l}21.80 \\
21.20\end{array}$ & $\begin{array}{l}34.99 \\
35.40\end{array}$ & 0455 & - & Standard \\
\hline $\begin{array}{l}\text { Est. } 9 \\
\text { M } 39 \\
\text { "Igaraty" }\end{array}$ & $28 / 6 / 54$ & $\begin{array}{l}24^{\circ} 33^{\prime} \mathrm{S} \\
45^{\circ} 27^{\prime} \mathrm{W}\end{array}$ & $6 y$ & $30-0$ & $\begin{array}{l}21.70 \\
17.80\end{array}$ & $\begin{array}{l}35.01 \\
35.90\end{array}$ & 0915 & - & Standard \\
\hline $\begin{array}{l}\text { Est. } 10 \\
\text { M } 40-51 \\
\text { "Igaraty" }\end{array}$ & $28 / 6 / 54$ & $\begin{array}{l}240^{\circ} 6^{\prime} \mathrm{S} \\
45^{\circ} 43^{\prime} \mathrm{W}\end{array}$ & - & supert. & - & - & 1330 & - & Standard \\
\hline $\begin{array}{l}\text { Est. 11 } \\
\text { M 56-64 } \\
\text { "Igaraty" }\end{array}$ & $29 / 6 / 54$ & $\begin{array}{l}24004^{\prime} \mathrm{S} \\
46007^{\prime} \mathrm{W}\end{array}$ & - & ${ }_{H}^{2}$ & 21.28 & 33.63 & 1415 & 12 & Standard \\
\hline $\begin{array}{l}\text { Est. 1 } \\
\text { M } 65 \\
\text { "Ungava" }\end{array}$ & $12 / 7 / 55$ & $\begin{array}{l}23057^{\prime} \mathrm{S} \\
45^{\circ} 46^{\prime} \mathrm{W}\end{array}$ & 18 & $\begin{array}{c}5 \\
\mathrm{H}\end{array}$ & - & - & 1000 & 15 & $50 \mathrm{~cm}$ \\
\hline $\begin{array}{l}\text { Est. } 2 \\
\text { M } 66 \\
\text { "Ungava" }\end{array}$ & $13 / 7 / 55$ & $\begin{array}{l}23015 ' \mathrm{~S} \\
44030^{\prime} \mathrm{W}\end{array}$ & 36 & fundo & - & - & 0755 & 15 & $50 \mathrm{~cm}$ \\
\hline $\begin{array}{l}\text { Est. }{ }^{3} \\
\text { M } 67 \\
\text { "Ungava" }\end{array}$ & $13 / 7 / 55$ & $\begin{array}{l}23004^{\prime} \mathrm{S} \\
44^{\circ} 14^{\prime} \mathrm{W}\end{array}$ & 52 & $\mathrm{~V}^{40}$ & - & - & 1030 & 5 & $50 \mathrm{~cm}$ \\
\hline $\begin{array}{l}\text { Est. } 4 \\
\text { M } 68 \\
\text { "Ungava" }\end{array}$ & $13 / 7 / 55$ & $\begin{array}{l}23004^{\prime} \mathrm{S} \\
44014^{\prime} \mathrm{W}\end{array}$ & 52 & $\mathrm{~V}^{40}$ & - & - & 1100 & 15 & $50 \mathrm{~cm}$ \\
\hline $\begin{array}{l}\text { Est. } 5 \\
\text { M } 69 \\
\text { "Ungava" }\end{array}$ & $13 / 7 / 55$ & $\begin{array}{l}23004^{\prime} \mathrm{S} \\
44014^{\prime} \mathrm{W}\end{array}$ & 52 & $\begin{array}{c}2 \\
\text { superf. }\end{array}$ & - & - & 1100 & 15 & $50 \mathrm{~cm}$ \\
\hline $\begin{array}{l}\text { تst. } 6 \\
\text { M } 70 \\
\text { "Ungava" }\end{array}$ & $27 / 10 / 55$ & $\begin{array}{l}\text { Região de } \\
\text { Cananéia }\end{array}$ & 12 & $\begin{array}{l}6 \\
\mathrm{H}\end{array}$ & - & - & 1630 & 5 & $50 \mathrm{~cm}$ \\
\hline $\begin{array}{l}\text { Est. } 7 \\
\text { M 71 } \\
\text { "Ungava" }\end{array}$ & $27 / 10 / 55$ & $\begin{array}{l}\text { Região de } \\
\text { Cananéia }\end{array}$ & - & $\begin{array}{l}6 \\
\mathrm{H}\end{array}$ & - & - & 1645 & 5 & $50 \mathrm{~cm}$ \\
\hline $\begin{array}{l}\text { Est. } 8 \\
\text { M } 72 \\
\text { "Ungava" }\end{array}$ & $27 / 10 / 55$ & $\begin{array}{l}\text { Região de } \\
\text { Cananéia }\end{array}$ & - & $\begin{array}{l}6 \\
\mathrm{H}\end{array}$ & - & - & 1710 & 5 & $50 \mathrm{~cm}$ \\
\hline $\begin{array}{l}\text { Est. } 1 \\
\text { M } 73 \\
\text { "P. Vargas" }\end{array}$ & $25 / 9 / 55$ & $\begin{array}{l}24011.8^{\prime} \mathrm{S} \\
45038.5^{\prime} \mathrm{W}\end{array}$ & 47 & superf. & 19.79 & 34.52 & 0915 & - & Standard \\
\hline $\begin{array}{l}\text { sst. } 2 \\
\text { M } 74 \\
\text { "P. Vargas" }\end{array}$ & $25 / 9 / 55$ & $\begin{array}{l}24044.8^{\prime} \mathrm{S} \\
45059^{\prime} \mathrm{W}\end{array}$ & 70 & $10 \overline{\mathrm{V}} 0$ & $\begin{array}{l}20.70 \\
20.20\end{array}$ & $\begin{array}{l}33.23 \\
33.30\end{array}$ & 1605 & - & Standard \\
\hline $\begin{array}{l}\text { تst. } 3 \\
\text { M } 75 \\
\text { 'P. Vargas" }\end{array}$ & $25 / 9 / 55$ & $\begin{array}{l}25015^{\prime} \mathrm{S} \\
46018^{\prime} \mathrm{W}\end{array}$ & 113 & $50 \bar{v}^{10}$ & $\begin{array}{l}20.19 \\
18.72\end{array}$ & $\begin{array}{l}33 . \overline{36} \\
35.86\end{array}$ & 2105 & 1 & Stondard \\
\hline
\end{tabular}


POR ESPÉCIE, ENCONTRADOS EM CADA AMOSTRA

\begin{tabular}{|c|c|c|c|c|c|c|c|c|c|c|c|}
\hline & $\cdot$ & & $\mathbf{S A G}$ & I T A & & & & PTEROS. & KROHIN. & & \\
\hline bip. & enfl. & frid. & glor. & hex. & hisp. & $\min$. & serrat. & draco & pacifica & $\begin{array}{l}\text { indiv. } \\
\text { jovens }\end{array}$ & TOTAI. \\
\hline - & - & - & - & - & - & - & - & - & - & $\begin{array}{c}8 \\
100 \%\end{array}$ & 8 \\
\hline- & $85.71 \%$ & $14.28 \%$ & - & - & - & - & - & - & - & - & 7 \\
\hline - & $50.00 \%$ & - & - & - & - & - & - & - & - & $50.00 \%$ & 2 \\
\hline $\begin{array}{c}1 \\
3,22 \%\end{array}$ & $\frac{11}{35.48 \%}$ & - & - & - & - & 一 & - & - & - & $\begin{array}{c}19 \\
61.29 \%\end{array}$ & 31 \\
\hline - & $76.10 \%$ & $1.02 \%$ & 一 & - & $\begin{array}{c}14 \\
4.77 \%\end{array}$ & $13.99 \%$ & $\begin{array}{c}4 \\
1.36 \%\end{array}$ & - & - & $2.73 \%$ & 293 \\
\hline - & $\stackrel{8}{8} 17.39 \%$ & $2.17 \%$ & - & - & 一 & - & $47.82 \%$ & - & - & $\begin{array}{c}15 \\
32.60 \%\end{array}$ & 46 \\
\hline - & $11.76 \%$ & - & - & - & - & - & $26.47 \%$ & $2.94 \%$ & - & $\begin{array}{c}20 \\
58.82 \%\end{array}$ & 34 \\
\hline- & $75.00 \%$ & - & - & $\begin{array}{c}4 \\
9.09 \%\end{array}$ & $\begin{array}{c}4 \\
9.09 \%\end{array}$ & $6.81 \%$ & - & - & - & - & 44 \\
\hline- & $\begin{array}{c}10 \\
90.90 \%\end{array}$ & - & - & - & $\frac{1}{9.09 \%}$ & - & - & - & - & - & 11 \\
\hline- & $\begin{array}{c}3.995 \\
50.96 \%\end{array}$ & $\begin{array}{c}915 \\
11.67 \%\end{array}$ & - & - & 13.032 & - & - & - & $\begin{array}{c}33 \\
0.42 \%\end{array}$ & $\begin{array}{c}1.863 \\
23.76 \%\end{array}$ & 7.838 \\
\hline - & $\begin{array}{c}2.250 \\
99.38 \%\end{array}$ & - & - & 一 & 一 & $0.13 \%$ & - & 一 & $\begin{array}{c}11 \\
0.48 \%\end{array}$ & - & 2.264 \\
\hline- & $\begin{array}{c}8 \\
38.09 \%\end{array}$ & - & - & - & $14.28 \%$ & - & - & - & - & $47.61 \%$ & 21 \\
\hline- & $\begin{array}{c}55 \\
36.66 \%\end{array}$ & - & - & - & $\begin{array}{c}2 \\
1.13 \%\end{array}$ & 一 & - & - & - & $62.00 \%$ & 150 \\
\hline- & $\begin{array}{c}23 \\
19.49 \%\end{array}$ & $16.10 \%$ & - & - & $\begin{array}{c}29 \\
24.57 \%\end{array}$ & - & - & - & - & $\begin{array}{c}47 \\
39.83 \%\end{array}$ & 118 \\
\hline- & $\begin{array}{c}67 \\
38.06 \%\end{array}$ & - & - & $\stackrel{1}{0.56 \%}$ & $\begin{array}{c}43 \\
24.43 \%\end{array}$ & - & - & 一 & - & $\begin{array}{c}65 \\
36.93 \%\end{array}$ & 176 \\
\hline $1.19 \%$ & $57.14 \%$ & $1.19 \%$ & - & - & $\begin{array}{c}17 \\
20.23 \%\end{array}$ & - & - & - & - & $\begin{array}{c}17 \\
20.23 \%\end{array}$ & 84 \\
\hline- & - & - & - & - & - & - & - & - & - & - & - \\
\hline- & - & - & - & - & - & - & - & - & - & - & - \\
\hline - & - & - & - & - & - & - & - & - & - & - & - \\
\hline - & $50.00 \%$ & - & - & - & $\frac{1}{50.00 \%}$ & - & - & - & - & - & 2 \\
\hline- & $100.00 \%$ & - & - & - & - & - & - & - & - & - & 26 \\
\hline - & $100.00 \%$ & - & - & - & - & - & - & - & - & - & 28 \\
\hline
\end{tabular}




\begin{tabular}{|c|c|c|c|c|c|c|c|c|c|}
\hline Amostra & Data & Posição & $\begin{array}{l}\text { Prof. } \\
\text { local } \\
\text { (m) }\end{array}$ & $\begin{array}{l}\text { Prof. da } \\
\text { coleta } \\
\text { (m) }\end{array}$ & $\begin{array}{l}\text { Temp. } \\
\text { oC }\end{array}$ & $\underset{0 / \infty 0}{S}$ & Hora & $\begin{array}{l}\text { Duração } \\
\text { do lance } \\
\text { (min.) }\end{array}$ & $\begin{array}{l}\text { Tipo } \\
\text { de rêde }\end{array}$ \\
\hline $\begin{array}{l}\text { Est. } 3 \\
M \\
M \\
\text { "P. Vargas" }\end{array}$ & $25 / 9 / 55$ & $\begin{array}{l}25015^{\prime} \mathrm{S} \\
46018^{\prime} \mathrm{W}\end{array}$ & 113 & $95 \frac{-}{V} 50$ & $\begin{array}{l}18.12 \\
16.00\end{array}$ & $\begin{array}{l}35.86 \\
35.59\end{array}$ & 2050 & - & Standard \\
\hline $\begin{array}{l}\text { Est. } 4 \\
\text { M } 77 \\
\text { "P. Vargas" }\end{array}$ & $26 / 9 / 55$ & $\begin{array}{c}25045.5^{\prime} \mathrm{S} \\
46^{\circ} 36.9^{\prime} \mathrm{W}\end{array}$ & 125 & ${ }^{54}-0$ & $\begin{array}{l}20.55 \\
17.53\end{array}$ & $\begin{array}{l}33.64 \\
35.77\end{array}$ & 0150 & - & Standard \\
\hline $\begin{array}{l}\text { Est. } 4 \\
\text { M } 78 \\
\text { "P. Vargas" }\end{array}$ & $26 / 9 / 55$ & $\begin{array}{c}25045.5^{\prime} \mathrm{S} \\
46^{\circ} 36.9^{\prime} \mathrm{W}\end{array}$ & 125 & ${ }^{108} \mathrm{~V}^{-54}$ & $\begin{array}{l}17.53 \\
12.48\end{array}$ & $\begin{array}{l}35.77 \\
35.10\end{array}$ & 0140 & - & Standard \\
\hline $\begin{array}{l}\text { Est. } 5 \\
\text { M } 79 \\
\text { "P. Vargas" }\end{array}$ & $26 / 9 / 55$ & $\begin{array}{l}26019.7^{\prime} \mathrm{S} \\
46058.5^{\prime} \mathrm{W}\end{array}$ & 130 & $120-0$ & $\begin{array}{l}20.30 \\
14.64\end{array}$ & $\begin{array}{l}33.88 \\
35.43\end{array}$ & 0615 & - & Standard \\
\hline $\begin{array}{l}\text { Est. } 6 \\
\mathrm{M} 80^{\circ} \\
\text { "P. Vargas" }\end{array}$ & $26 / 9 / 55$ & $\begin{array}{l}27009.4^{\prime} \mathrm{S} \\
47016.5^{\prime} \mathrm{W}\end{array}$ & 125 & $125-0$ & $\begin{array}{l}20.99 \\
13.71\end{array}$ & $\begin{array}{l}35.24 \\
35.66\end{array}$ & 1240 & - & Standard \\
\hline $\begin{array}{l}\text { Est. }{ }^{7} \\
\text { M } 81 \\
\text { "P. Vargas" }\end{array}$ & $26 / 9 / 55$ & $\begin{array}{l}27036.5 ' \mathrm{~S} \\
47056^{\prime} \mathrm{W}\end{array}$ & 95 & $46 \frac{-0}{V}$ & $\begin{array}{l}20.42 \\
20.36\end{array}$ & $\begin{array}{l}34.31 \\
36.06\end{array}$ & 1720 & - & Standard \\
\hline $\begin{array}{l}\text { Est. } 7 \\
\text { M } 82 \\
\text { "P. Vargas" }\end{array}$ & $26 / 9 / 55$ & $\begin{array}{l}27036.5^{\prime} \mathrm{S} \\
47056^{\prime} \mathrm{W}\end{array}$ & 95 & $92 \bar{v}^{46}$ & $\begin{array}{l}20.36 \\
19.64\end{array}$ & $\begin{array}{l}36.06 \\
34.70\end{array}$ & 1700 & - & Standard \\
\hline $\begin{array}{l}\text { Est. } 8 \\
\text { M } 83 \\
\text { "P. Vargas" }\end{array}$ & $26 / 9 / 55$ & $\begin{array}{l}28007.5^{\prime} \mathrm{S} \\
48012^{\prime} \mathrm{W}\end{array}$ & 63 & $60 \frac{\mathrm{V}}{0}$ & $\begin{array}{l}19.00 \\
17.14\end{array}$ & $\begin{array}{l}33.47 \\
35.70\end{array}$ & 2205 & - & Standard \\
\hline $\begin{array}{l}\text { Est. } 9 \\
\text { M } 84 \\
\text { "P. Vargas" }\end{array}$ & $27 / 9 / 55$ & $\begin{array}{l}28053^{\prime} \mathrm{S} \\
48045^{\prime} \mathrm{W}\end{array}$ & 61 & $61 \bar{v}^{0}$ & $\begin{array}{l}19.10 \\
17.35\end{array}$ & $\begin{array}{l}33.86 \\
35.90\end{array}$ & 0425 & - & Standard \\
\hline $\begin{array}{l}\text { Est. } 12 \\
\text { M } 85 \\
\text { "P. Vargas" }\end{array}$ & $28 / 9 / 55$ & $\begin{array}{l}30^{\circ} 179^{\prime} \mathrm{S} \\
49.18^{\prime} \mathrm{W}\end{array}$ & 106 & $50 \frac{-0}{\mathrm{~V}}$ & $\begin{array}{l}18.94 \\
19.31\end{array}$ & $\begin{array}{l}34.54 \\
35.26\end{array}$ & 1950 & - & Standard \\
\hline $\begin{array}{l}\text { Est. } 12 \\
\text { M } 86 \\
\text { "P. Vargas" }\end{array}$ & $28 / 9 / 55$ & $\begin{array}{l}30^{\circ} 179^{\prime} \mathrm{S} \\
49.18^{\prime} \mathrm{W}\end{array}$ & 106 & $100-50$ & $\begin{array}{l}19.31 \\
16.50\end{array}$ & $\begin{array}{l}35.26 \\
35.71\end{array}$ & 1945 & - & Standard \\
\hline $\begin{array}{l}\text { Est. } 13 \\
\text { M } 87 \\
\text { "P. Vargas" }\end{array}$ & $29 / 9 / 55$ & $\begin{array}{l}30022 \text { 'S } \\
49019^{\prime} \mathrm{W}\end{array}$ & 120 & $110-0$ & $\begin{array}{l}18.60 \\
18.61\end{array}$ & $\begin{array}{l}34.06 \\
35.90\end{array}$ & 0050 & - & Standard \\
\hline $\begin{array}{l}\text { Est. } 18 \\
\text { M } 88 \\
\text { "P. Vargas" }\end{array}$ & $5 / 10 / 55$ & $\begin{array}{l}32023.5^{\prime} \mathrm{S} \\
52 \circ 03.3^{\prime} \mathrm{W}\end{array}$ & 20 & $12 \overline{\mathrm{V}}^{0}$ & $\begin{array}{l}15.40 \\
15.37\end{array}$ & $\begin{array}{l}25.49 \\
33.22\end{array}$ & 1930 & - & Standard \\
\hline $\begin{array}{l}\text { Est. } 19 \\
\text { M } 89 \\
\text { "P. Vargas" }\end{array}$ & $6 / 10 / 55$ & $\begin{array}{l}32033^{\prime} \mathrm{S} \\
51058.5 \mathrm{~W}\end{array}$ & 25 & $22-0$ & $\begin{array}{l}15.00 \\
14.38\end{array}$ & $\begin{array}{l}31.78 \\
32.57\end{array}$ & 0050 & - & Standard \\
\hline $\begin{array}{l}\text { Est. } 24 \\
\text { M 90 } \\
\text { P. Vargas }\end{array}$ & $7 / 10 / 55$ & $\begin{array}{l}31015.2^{\prime} \mathrm{S} \\
50036.7^{\prime} \mathrm{W}\end{array}$ & 27 & $25 \frac{\mathrm{V}}{0}$ & $\begin{array}{l}17.81 \\
17.36\end{array}$ & $\begin{array}{l}33.77 \\
35.82\end{array}$ & 1637 & - & Standard \\
\hline $\begin{array}{l}\text { Est. }{ }^{1} \\
\text { M } 91 \\
\text { "Solimões" }\end{array}$ & $26 / 2 / 56$ & $\begin{array}{l}24{ }^{\circ} 08^{\prime} \mathrm{S} \\
46^{\circ} 11.5^{\prime} \mathrm{W}\end{array}$ & 28 & $10 \overline{\mathrm{H}} 0$ & $\begin{array}{l}27.07 \\
26.95\end{array}$ & $\begin{array}{l}33.55 \\
34.97\end{array}$ & 0840 & 7 & Standard \\
\hline $\begin{array}{l}\text { Est. } 2 \\
\text { M 92 } \\
\text { "Solimöes" }\end{array}$ & $26 / 2 / 56$ & $\begin{array}{l}24015^{\prime} \mathrm{S} \\
46003.8^{\prime} \mathrm{W}\end{array}$ & 44 & ${ }^{10}-0$ & $\begin{array}{l}26.93 \\
26.24\end{array}$ & $\begin{array}{l}35.15 \\
35.15\end{array}$ & 1035 & 10 & Standard \\
\hline $\begin{array}{l}\text { Est. }{ }^{3} \\
\text { M 93 } \\
\text { "Solimões" }\end{array}$ & $26 / 2 / 56$ & $\begin{array}{l}24^{\circ} 29^{\prime} \mathrm{S} \\
45^{\circ} 48.2^{\prime} \mathrm{W}\end{array}$ & 60 & $10 \frac{-}{\mathrm{H}} 0$ & $\begin{array}{l}26.34 \\
25.21\end{array}$ & $\begin{array}{l}35.18 \\
35.18\end{array}$ & 1345 & 10 & Standard \\
\hline $\begin{array}{l}\text { Est. } 4 \\
\text { M } 94 \\
\text { "Solimões" }\end{array}$ & $26 / 2 / 56$ & $\begin{array}{l}24058^{\prime} \mathrm{S} \\
45043^{\prime} \mathrm{W}\end{array}$ & 90 & $10 \frac{-}{\mathrm{H}} 0$ & $\begin{array}{l}26.30 \\
24.54\end{array}$ & $\begin{array}{l}35.34 \\
35.68\end{array}$ & 1718 & 10 & Standard \\
\hline $\begin{array}{l}\text { Est. } 5 \\
\text { M 95 } \\
\text { "Solimões" }\end{array}$ & $26 / 2 / 56$ & $\begin{array}{l}25^{\circ} 19^{\prime} \mathrm{S} \\
45^{\circ} 21 \mathrm{~W}\end{array}$ & 135 & $10 \frac{-}{\mathrm{H}} 0$ & $\begin{array}{l}25.80 \\
25.78\end{array}$ & $\begin{array}{l}35.84 \\
36.94\end{array}$ & 2010 & 10 & Standard \\
\hline $\begin{array}{l}\text { Est. } 7 \\
\text { M 96 } \\
\text { "Solimões" }\end{array}$ & $27 / 2 / 56$ & $\begin{array}{l}26048^{\prime} \mathrm{S} \\
43019.3^{\prime} \mathrm{W}\end{array}$ & 2.571 & $10 \frac{\mathrm{H}}{-0}$ & $\begin{array}{l}25.93 \\
25.90\end{array}$ & $\begin{array}{l}36.52 \\
36.51\end{array}$ & 1107 & - & Standard \\
\hline $\begin{array}{l}\text { Est. } 10 \\
\text { M } 97 \\
\text { "Solimões" }\end{array}$ & $28 / 2 / 56$ & $\begin{array}{l}25039^{\prime} \mathrm{S} \\
42052^{\prime} \mathrm{W}\end{array}$ & 2.250 & $10 \frac{-}{\mathrm{H}} 0$ & $\begin{array}{l}26.46 \\
26.21\end{array}$ & $\begin{array}{l}36.86 \\
36.82\end{array}$ & 1045 & - & Standard \\
\hline
\end{tabular}




\begin{tabular}{|c|c|c|c|c|c|c|c|c|c|c|c|}
\hline & & & S A G I & T T A & & & & PTEROS. & KROHN. & Total & - \\
\hline bip. & enfl. & frid. & glor. & hex. & hisp. & $\min$. & serrat. & draco & pacifica & $\begin{array}{l}\text { indiv. } \\
\text { jovens }\end{array}$ & TOTAI \\
\hline- & $\begin{array}{c}20 \\
100.00 \%\end{array}$ & - & - & - & - & - & - & - & - & - & 20 \\
\hline - & $\begin{array}{c}44 \\
78.57 \%\end{array}$ & - & - & - & - & $21.43 \%$ & - & - & - & - & 56 \\
\hline- & $\begin{array}{c}18 \\
69.23 \%\end{array}$ & - & - & - & - & $\begin{array}{c}8 \\
30.77 \%\end{array}$ & - & - & - & - & 26 \\
\hline- & - & - & - & - & - & - & - & - & - & - & - \\
\hline- & $\begin{array}{c}21 \\
56.26 \%\end{array}$ & $\stackrel{1}{1}$ & - & - & $\begin{array}{c}3 \\
7.89 \%\end{array}$ & $31.58 \%$ & $2.63 \%$ & - & - & - & 38 \\
\hline- & $\stackrel{1}{14} \%$ & - & - & - & $14.28 \%$ & $\begin{array}{c}5 \\
71.43 \%\end{array}$ & - & - & - & - & 7 \\
\hline- & $29.17 \%$ & - & - & - & - & $\begin{array}{l}16 \\
66.67 \%\end{array}$ & $4.17 \%$ & - & - & - & 24 \\
\hline - & $\begin{array}{c}4 \\
80.00 \%\end{array}$ & 一 & - & - & - & $20.00 \%$ & - & - & - & - & 5 \\
\hline - & $\begin{array}{c}17 \\
73.91 \%\end{array}$ & - & - & - & $\begin{array}{c}5 \\
21.74 \%\end{array}$ & $4.35 \%$ & - & - & - & - & 23 \\
\hline- & $13.33 \%$ & - & - & - & - & $80.00 \%$ & - & - & - & $6.67 \%$ & 15 \\
\hline- & - & - & - & - & $100.00 \%$ & - & - & - & - & - & 2 \\
\hline- & $\begin{array}{c}64 \\
52.90 \%\end{array}$ & - & - & - & $2.38 \%$ & $43.80 \%$ & $0.82 \%$ & - & - & - & 121 \\
\hline- & - & - & - & - & - & $100.00 \%$ & - & - & - & - & 4 \\
\hline- & - & $33.33 \%$ & - & - & $\begin{array}{c}2 \\
66.67 \%\end{array}$ & - & - & - & - & - & 3 \\
\hline- & - & $\begin{array}{c}21 \\
87.50 \%\end{array}$ & - & - & $\begin{array}{c}2 \\
8.33 \%\end{array}$ & - & - & - & - & $4.17 \%$ & 24 \\
\hline- & $\begin{array}{c}245 \\
50.31 \%\end{array}$ & $12.52 \%$ & - & $\stackrel{2}{0.41 \%}$ & $\begin{array}{c}108 \\
22.18 \%\end{array}$ & - & - & - & - & $\begin{array}{c}71 \\
14.58 \%\end{array}$ & 487 \\
\hline - & $\begin{array}{c}49 \\
11.26 \%\end{array}$ & - & - & - & $20.92 \%$ & - & - & - & - & $\begin{array}{c}295 \\
67.82 \%\end{array}$ & 435 \\
\hline- & $\begin{array}{c}190 \\
21.44 \%\end{array}$ & - & $46.39 \%$ & $\begin{array}{c}62 \\
7.00 \%\end{array}$ & - & - & $0.11 \%$ & - & - & 2222 & 886 \\
\hline- & - & - & - & - & - & - & - & - & - & - & - \\
\hline $1,44 \%$ & $\begin{array}{c}108 \\
52.17 \%\end{array}$ & - & - & $0.48 \%$ & $\begin{array}{c}41 \\
19.81 \%\end{array}$ & $0.97 \%$ & $3.86 \%$ & - & - & $\begin{array}{c}44 \\
21.26 \%\end{array}$ & 207 \\
\hline- & - & - & - & - & - & - & - & - & - & - & - \\
\hline $10.00 \%$ & - & - & - & - & - & - & - & - & - & $90.90 \%$ & 10 \\
\hline
\end{tabular}




\begin{tabular}{|c|c|c|c|c|c|c|c|c|c|}
\hline Amostra & Data & Posição & $\begin{array}{l}\text { Prof. } \\
\text { local } \\
\text { (m) }\end{array}$ & $\begin{array}{l}\text { Prof. da } \\
\text { coleta } \\
(\mathrm{m})\end{array}$ & $\underset{\text { OC }}{\text { Temp. }}$ & Salin. & Hora & $\begin{array}{c}\text { Duração } \\
\text { do lance } \\
\text { (min.) }\end{array}$ & de rêde \\
\hline $\begin{array}{l}\text { Est. 11 } \\
\text { M 98 } \\
\text { "Solimões" }\end{array}$ & $28 / 2 / 56$ & $\begin{array}{l}24051^{\prime} \mathrm{S} \\
42059^{\prime} \mathrm{W}\end{array}$ & 2.000 & $10 \frac{\mathrm{H}}{\mathrm{O}} \mathrm{O}$ & $\begin{array}{l}25.43 \\
25.14\end{array}$ & $\begin{array}{l}36.47 \\
36.47\end{array}$ & 1605 & 15 & Standard \\
\hline $\begin{array}{l}\text { Est. } 12 \\
\text { M } 99 \\
\text { "Solimões" }\end{array}$ & $28 / 2 / 56$ & $\begin{array}{l}240^{\circ} 22^{\prime} \mathrm{S} \\
43004^{\prime} \mathrm{W}\end{array}$ & 1.000 & $10 \frac{-\mathrm{H}}{0}$ & $\begin{array}{l}24.89 \\
24.74\end{array}$ & $\begin{array}{l}36.49 \\
36.46\end{array}$ & 1912 & 30 & Standard \\
\hline $\begin{array}{l}\text { Est. } 13 \\
\text { M ioo } \\
\text { "Solimões" }\end{array}$ & $28 / 2 / 56$ & $\begin{array}{l}24001^{\prime} \mathrm{S} \\
43003^{\prime} \mathrm{W}\end{array}$ & 410 & $10 \overline{\mathrm{H}} 0$ & $\begin{array}{l}22.78 \\
22.53\end{array}$ & $\begin{array}{l}3606 \\
36.06\end{array}$ & 2157 & 45 & Standard \\
\hline $\begin{array}{l}\text { Est. } 19 \\
\text { M 101 } \\
\text { "Solimões" } \\
\end{array}$ & $5 / 3 / 56$ & $\begin{array}{l}23^{\circ} 04^{\prime} \mathrm{S} \\
42^{\circ} 34^{\prime} \mathrm{W}\end{array}$ & 61 & ${ }_{\mathrm{H}}-0$ & 25.90 & 34.69 & 1210 & - & $\begin{array}{c}\text { Clarke } \\
\text { Bumpus }\end{array}$ \\
\hline $\begin{array}{l}\text { Est. } 20 \\
\text { M } 102 \\
\text { "Solimões" }\end{array}$ & $5 / 3 / 56$ & $\begin{array}{l}23004^{\prime} \mathrm{S} \\
42^{\circ} 17^{\prime} \mathrm{W}\end{array}$ & 75 & ${ }_{\mathrm{H}}^{5-0}$ & 25.56 & 35.00 & 1405 & - & $\begin{array}{l}\text { Clarke } \\
\text { Bumpus }\end{array}$ \\
\hline $\begin{array}{l}\text { Est. }{ }^{21} \\
\mathrm{M} 103 \\
\text { "Solimões" }\end{array}$ & $5 / 3 / 56$ & $\begin{array}{l}23004^{\prime} \mathrm{S} \\
41058.5^{\prime} \mathrm{W}\end{array}$ & 85 & $10 \frac{-}{\mathrm{H}} 0$ & $\begin{array}{l}25.50 \\
24.36\end{array}$ & $\begin{array}{l}34.74 \\
34.74\end{array}$ & 1600 & - & $\begin{array}{l}\text { Clarke } \\
\text { Bumpus }\end{array}$ \\
\hline $\begin{array}{l}\text { Est. } 22 \\
\text { M } 104 \\
\text { "Solimões" }\end{array}$ & $5 / 3 / 56$ & $\begin{array}{l}23017.5^{\prime} \mathrm{S} \\
41051,5^{\prime} \mathrm{W}\end{array}$ & 125 & $10 \frac{-0}{\mathrm{H}}$ & $\begin{array}{l}22.90 \\
22.06\end{array}$ & $\begin{array}{l}35.96 \\
36.00\end{array}$ & 1743 & - & $\begin{array}{l}\text { Clarke } \\
\text { Bumpus }\end{array}$ \\
\hline $\begin{array}{l}\text { Est. 23 } \\
\text { M 105 } \\
\text { "Solimões" }\end{array}$ & $5 / 3 / 56$ & $\begin{array}{l}23038^{\prime} \mathrm{S} \\
41046^{\prime} \mathrm{W}\end{array}$ & 132 & $10 \frac{-}{\mathrm{H}} 0$ & $\begin{array}{l}20.80 \\
18.93\end{array}$ & $\begin{array}{l}35.69 \\
35.54\end{array}$ & 2000 & - & $\begin{array}{l}\text { Clarke } \\
\text { Bumpus }\end{array}$ \\
\hline $\begin{array}{l}\text { Est. 24 } \\
\text { M 106 } \\
\text { "Solimões" }\end{array}$ & $5 / 3 / 56$ & $\begin{array}{l}24000^{\prime} \mathrm{S} \\
41^{\circ} 31^{\prime} \mathrm{W}\end{array}$ & 1.304 & $10 \frac{-0}{\mathrm{H}}$ & $\begin{array}{l}25.80 \\
26.36\end{array}$ & $\begin{array}{l}36.85 \\
36.85\end{array}$ & 2253 & - & $\begin{array}{l}\text { Clarke } \\
\text { Bumpus }\end{array}$ \\
\hline $\begin{array}{l}\text { Est. } 32 \\
\text { M } 107 \\
\text { "Solimões" }\end{array}$ & $7 / 3 / 56$ & $\begin{array}{l}23058.5^{\prime} \mathrm{S} \\
45^{\circ} 30^{\prime} \mathrm{W}\end{array}$ & 42 & $10 \frac{-0}{\mathrm{H}}$ & $\begin{array}{l}27.22 \\
26.50\end{array}$ & $\begin{array}{l}33.78 \\
34.78\end{array}$ & 0410 & - & $\begin{array}{l}\text { Clarke } \\
\text { Bumpus }\end{array}$ \\
\hline $\begin{array}{l}\text { Est. } 33 \\
\text { M } 108 \\
\text { "Solimões" } \\
\end{array}$ & $7 / 3 / 56$ & $\begin{array}{l}24000.5^{\prime} \mathrm{S} \\
45052^{\prime} \mathrm{W}\end{array}$ & 28 & $5 \overline{\mathrm{H}} 0$ & 26.50 & 34.30 & 0610 & - & $\begin{array}{l}\text { Clarke } \\
\text { Bumpus }\end{array}$ \\
\hline $\begin{array}{l}\text { Est. } 37 \\
\text { M } 109 \\
\text { "Iguatemy" }\end{array}$ & $14 / 6 / 56$ & $\begin{array}{l}24051^{\prime} \mathrm{S} \\
45^{\circ} 25^{\prime} \mathrm{W}\end{array}$ & 88 & $10 \frac{\mathrm{H}}{0}$ & $\begin{array}{l}20.89 \\
20.74\end{array}$ & $\begin{array}{l}36.18 \\
36.18\end{array}$ & 1645 & - & $\begin{array}{l}\text { Clarke } \\
\text { Bumpus }\end{array}$ \\
\hline $\begin{array}{l}\text { Est. } 38 \\
\text { M } 110 \\
\text { "Iguatemy" }\end{array}$ & $14 / 6 / 56$ & $\begin{array}{l}25013^{\prime} \mathrm{S} \\
45^{\circ} 02^{\prime} \mathrm{W}\end{array}$ & 135 & $10_{\mathrm{H}} 0$ & $\begin{array}{l}22.48 \\
22.39\end{array}$ & $\begin{array}{l}36.70 \\
36.57\end{array}$ & 2025 & - & $\begin{array}{l}\text { Clarke } \\
\text { Bumpus }\end{array}$ \\
\hline $\begin{array}{l}\text { Est. } 39 \\
\text { M 111 } \\
\text { "Iguatemy" }\end{array}$ & $14 / 6 / 56$ & $\begin{array}{l}25041^{\prime} \mathrm{S} \\
44031^{\prime} \mathrm{W}\end{array}$ & 1.000 & $10 \frac{-0}{\mathrm{H}}$ & $\begin{array}{l}22.52 \\
22.56\end{array}$ & $\begin{array}{l}36.87 \\
36.83\end{array}$ & 0130 & - & $\begin{array}{l}\text { Clarke } \\
\text { Bumpus }\end{array}$ \\
\hline $\begin{array}{l}\text { Est. } 40 \\
\text { M } 112 \\
\text { "Iguatemy" }\end{array}$ & $15 / 6 / 56$ & $\begin{array}{l}26040^{\prime} \mathrm{S} \\
43059^{\prime} \mathrm{W}\end{array}$ & 2.000 & $10 \frac{-0}{\mathrm{H}}$ & $\begin{array}{l}21.90 \\
21.20\end{array}$ & $\begin{array}{l}36.45 \\
36.42\end{array}$ & 0610 & - & $\begin{array}{c}\text { Clarke } \\
\text { Bumpus }\end{array}$ \\
\hline $\begin{array}{l}\text { Est. } 41 \\
\text { M } 113 \\
\text { "Iguatemy" }\end{array}$ & $15 / 6 / 56$ & $\begin{array}{l}26045^{\prime} \mathrm{S} \\
43021^{\prime} \mathrm{W}\end{array}$ & 2.000 & $10 \frac{-}{\mathrm{H}} 0$ & $\begin{array}{l}21.60 \\
21.54\end{array}$ & $\begin{array}{l}36.48 \\
36.44\end{array}$ & 1200 & - & $\begin{array}{l}\text { Clarke } \\
\text { Bumpus }\end{array}$ \\
\hline $\begin{array}{l}\text { Est. } 43 \\
\text { M } 114 \\
\text { "Iguatemy" }\end{array}$ & $15 / 6 / 56$ & $\begin{array}{l}27015^{\prime} \mathrm{S} \\
43051^{\prime} \mathrm{W}\end{array}$ & 2.000 & superf. & 21.00 & 36.15 & $\begin{array}{l}2138 \\
2319\end{array}$ & - & Standard \\
\hline $\begin{array}{l}\text { Est. } 44 \\
\text { M 115 } \\
\text { "Iguatemy" }\end{array}$ & $16 / 6 / 56$ & $\begin{array}{l}27016^{\prime} \mathrm{S} \\
44054^{\prime} \mathrm{W}\end{array}$ & 2.000 & superf. & 22.39 & 36.74 & $\begin{array}{l}0325 \\
0436\end{array}$ & - & Standard \\
\hline $\begin{array}{l}\text { Est. } 46 \\
\text { M 116 } \\
\text { "Iguatemy" }\end{array}$ & $16 / 6 / 56$ & $\begin{array}{l}27018^{\prime} \mathrm{S} \\
46045^{\prime} \mathrm{W}\end{array}$ & 1.000 & superf. & 20.72 & 36.04 & 1503 & - & Standard \\
\hline $\begin{array}{l}\text { Est. } 46 \\
\text { M } 117 \\
\text { "Iguatemy" }\end{array}$ & $16 / 6 / 56$ & $\begin{array}{l}27018^{\prime} \mathrm{S} \\
46045^{\prime} \mathrm{W}\end{array}$ & 1.000 & superf. & 20.72 & 36.04 & 1503 & - & Standard \\
\hline $\begin{array}{l}\text { Est. } 47 \\
\text { M } 118 \\
\text { "Iguatemy" }\end{array}$ & $16 / 6 / 56$ & $\begin{array}{l}27019^{\prime} \mathrm{S} \\
472^{\prime} 22^{\prime} \mathrm{W}\end{array}$ & 142 & $2-0$ & 21.08 & 36.25 & 1840 & - & Standard \\
\hline $\begin{array}{l}\text { Est. } 47 \\
\text { M } 119 \\
\text { "Iguatemy" }\end{array}$ & $16 / 6 / 56$ & $\begin{array}{l}27019^{\prime} \mathrm{S} \\
47022^{\prime} \mathrm{W}\end{array}$ & 142 & $\begin{array}{c}10 \mathrm{~m} \text { de } \\
\text { cabo }\end{array}$ & 21.08 & 36,25 & 1840 & - & $\begin{array}{l}\text { Clarke } \\
\text { Bumpus }\end{array}$ \\
\hline
\end{tabular}




\begin{tabular}{|c|c|c|c|c|c|c|c|c|c|c|c|}
\hline & & & S A G & T T A & & & & PTEROS. & KROHN. & Total & \\
\hline bip. & enfl. & frid. & glor. & hex. & hisp. & $\min$. & serrat. & draco & pacifica & $\begin{array}{l}\text { indiv. } \\
\text { jovens }\end{array}$ & TOTAL \\
\hline- & $\stackrel{1}{5,55 \%}$ & - & - & - & - & - & - & - & - & $\begin{array}{c}17 \\
94.44 \%\end{array}$ & 18 \\
\hline- & $\begin{array}{c}10 \\
6.21 \%\end{array}$ & - & - & - & - & - & $\begin{array}{c}67 \\
41.61 \%\end{array}$ & - & $1.24 \%$ & $\begin{array}{c}82 \\
50.93 \%\end{array}$ & 161 \\
\hline- & $\begin{array}{c}184 \\
92.00 \%\end{array}$ & - & - & - & $2.00 \%$ & - & - & $1.30 \%$ & - & $\begin{array}{c}9 \\
4.50 \%\end{array}$ & 200 \\
\hline- & $\begin{array}{c}23 \\
79.31 \%\end{array}$ & - & $6.90 \%$ & - & $\begin{array}{c}1 \\
3.45 \%\end{array}$ & - & - & - & - & $10.34 \%$ & 29 \\
\hline- & $92.06 \%$ & - & - & - & $\begin{array}{c}5 \\
7.94 \%\end{array}$ & - & - & - & - & - & 63 \\
\hline- & $\begin{array}{c}16 \\
72.73 \%\end{array}$ & - & - & - & $27 . \stackrel{6}{27} \%$ & - & - & - & - & - & 22 \\
\hline- & $3.57 \%$ & - & - & - & $10.31 \%$ & - & $25.00 \%$ & - & - & $\begin{array}{c}17 \\
60.71 \%\end{array}$ & 28 \\
\hline- & $9.46 \%$ & - & - & - & $1.35 \%$ & - & $\begin{array}{c}64 \\
86.49 \%\end{array}$ & - & - & $2.70 \%$ & 74 \\
\hline- & - & - & - & - & - & - & - & - & - & - & - \\
\hline- & $\begin{array}{c}141 \\
81.98 \%\end{array}$ & - & - & - & $\begin{array}{c}20 \\
11.63 \%\end{array}$ & - & - & - & - & $\begin{array}{c}11 \\
6.39 \%\end{array}$ & 172 \\
\hline - & $16.67 \%$ & - & - & - & $\begin{array}{c}5 \\
27.78 \%\end{array}$ & - & - & - & - & $\begin{array}{c}10 \\
55.55 \%\end{array}$ & 18 \\
\hline- & $\begin{array}{l}2 \\
66.67 \%\end{array}$ & - & - & - & - & - & - & - & - & $33.33 \%$ & 3 \\
\hline- & $100.00 \%$ & - & - & - & - & - & - & - & - & - & 6 \\
\hline- & $100.00 \%$ & - & - & - & - & - & - & - & - & - & 6 \\
\hline - & $\begin{array}{c}2 \\
66.67 \%\end{array}$ & $33.33 \%$ & - & - & - & - & - & - & - & - & 3 \\
\hline $5.40 \%$ & - & - & - & - & - & - & $\begin{array}{c}5 \\
13.51 \%\end{array}$ & - & - & 81.3 & 37 \\
\hline - & $\begin{array}{c}25 \\
15.06 \%\end{array}$ & - & - & $1.20 \%$ & - & $7.83 \%$ & $\begin{array}{c}119 \\
71.69 \%\end{array}$ & $\begin{array}{c}7 \\
4.22 \%\end{array}$ & - & - & 166 \\
\hline- & $\begin{array}{c}35 \\
26.51 \%\end{array}$ & $5.30 \%$ & - & - & - & - & $\begin{array}{c}78 \\
59.09 \%\end{array}$ & $\begin{array}{c}12 \\
9.09 \%\end{array}$ & - & - & 132 \\
\hline- & $\begin{array}{c}497 \\
51.72 \%\end{array}$ & $\begin{array}{c}5 \\
0.52 \%\end{array}$ & - & - & $\begin{array}{c}50 \\
5.00 \%\end{array}$ & $\begin{array}{l}66 \\
6.87 \%\end{array}$ & $\begin{array}{c}307 \\
-31.95 \%\end{array}$ & $\begin{array}{c}34 \\
3.54 \%\end{array}$ & - & $0.20 \%$ & 961 \\
\hline - & $\begin{array}{c}119 \\
44.08 \%\end{array}$ & - & - & - & $\begin{array}{c}13 \\
4.44 \%\end{array}$ & $\begin{array}{c}17 \\
6.30 \%\end{array}$ & $\begin{array}{c}115 \\
42.59 \%\end{array}$ & $\stackrel{7}{7}$. $59 \%$ & - & - & 270 \\
\hline $1.60 \%$ & $\begin{array}{l}212 \\
56.53 \%\end{array}$ & - & - & - & $1.87 \%$ & $2.13 \%$ & $\begin{array}{c}135 \\
36.00 \%\end{array}$ & $\begin{array}{c}7 \\
1.87 \%\end{array}$ & - & - & 375 \\
\hline- & $50.00 \%$ & - & - & - & - & - & $25.00 \%$ & - & - & $25.00 \%$ & 4 \\
\hline
\end{tabular}




\begin{tabular}{|c|c|c|c|c|c|c|c|c|c|}
\hline Amostra & Data & Posiçã̃o & $\begin{array}{l}\text { Prof. } \\
\text { local } \\
\text { (m) }\end{array}$ & $\begin{array}{l}\text { Prof. da } \\
\text { coleta } \\
(\mathrm{m})\end{array}$ & Temp. & Salin. & Hora & $\begin{array}{l}\text { Duração } \\
\text { do lance } \\
\text { (min.) }\end{array}$ & $\begin{array}{l}\text { Tipo } \\
\text { de rêdo }\end{array}$ \\
\hline $\begin{array}{l}\text { Est. } 48 \\
\text { M } 120 \\
\text { "Iguatemy" }\end{array}$ & $16 / 6 / 56$ & $\begin{array}{l}27019^{\prime} \mathrm{S} \\
470^{\circ} \mathrm{W}\end{array}$ & 115 & $\begin{array}{c}10 \mathrm{~m} \text { de } \\
\text { cabo }\end{array}$ & 20.63 & 35.90 & 1940 & - & Standard \\
\hline $\begin{array}{l}\text { Est. } 48 \\
\text { M 121 } \\
\text { "Iguatemy" }\end{array}$ & $16 / 6 / 56$ & $\begin{array}{l}27019^{\prime} \mathrm{S} \\
470^{\circ} 5^{\prime} \mathrm{W}\end{array}$ & 115 & $\begin{array}{c}10 \mathrm{~m} \mathrm{de} \\
\text { cabo }\end{array}$ & 20.63 & 35.90 & 1940 & - & $\begin{array}{c}\text { Clarke } \\
\text { Bumpus }\end{array}$ \\
\hline $\begin{array}{l}\text { Est. } 49 \\
\text { M } 122 \\
\text { "Iguatemy" }\end{array}$ & $16 / 6 / 56$ & $\begin{array}{l}27019^{\prime} \mathrm{S} \\
48013^{\prime} \mathrm{W}\end{array}$ & 63 & $\begin{array}{c}10 \mathrm{~m} \mathrm{de} \\
\text { cabo }\end{array}$ & 18.13 & 34.08 & 2400 & - & Standard \\
\hline $\begin{array}{l}\text { Est. } 50 \\
\text { M } 123 \\
\text { "Iguatemy" } \\
\end{array}$ & $17 / 6 / 56$ & $\begin{array}{l}26055^{\prime} \mathrm{S} \\
47049^{\prime} \mathrm{W}\end{array}$ & 90 & $\begin{array}{c}10 \mathrm{~m} \mathrm{de} \\
\text { cabo }\end{array}$ & 20.00 & 35.57 & 0313 & - & Standard \\
\hline $\begin{array}{l}\text { Est. } 51 \\
\text { M i24-5 } \\
\text { "Iguatemy" }\end{array}$ & $17 / 6 / 56$ & $\begin{array}{l}26028^{\prime} \mathrm{S} \\
47030^{\prime} \mathrm{W}\end{array}$ & 95 & $\begin{array}{c}10 \mathrm{~m} \mathrm{de} \\
\text { cabo }\end{array}$ & 19.58 & 35.56 & 0638 & - & Standard \\
\hline $\begin{array}{l}\text { Est. } 52 \\
\text { M 126-7 } \\
\text { "Iguatemy" }\end{array}$ & $17 / 6 / 56$ & $\begin{array}{l}26004 \text { 'S } \\
47014^{\prime} \mathrm{W}\end{array}$ & 99 & $\begin{array}{c}10 \mathrm{~m} \mathrm{de} \\
\text { cabo }\end{array}$ & 19.89 & 35.70 & 1000 & - & Standard \\
\hline $\begin{array}{l}\text { Est. } 53 \\
\text { M 128 } \\
\text { "Iguatemy" }\end{array}$ & $17 / 6 / 56$ & $\begin{array}{l}25038^{\prime} \mathrm{S} \\
46056^{\prime} \mathrm{W}\end{array}$ & 80 & 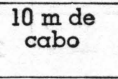 & 19.60 & 35.56 & 1300 & - & Standard \\
\hline $\begin{array}{l}\text { Est. } 54 \\
\text { M } 129-30 \\
\text { "Iguatemy" }\end{array}$ & $17 / 6 / 56$ & $\begin{array}{l}25013^{\prime} \mathrm{S} \\
46038^{\prime} \mathrm{W}\end{array}$ & 71 & $\begin{array}{c}10 \mathrm{~m} \text { de } \\
\text { cabo }\end{array}$ & 19.75 & 35.57 & 1600 & - & Standard \\
\hline $\begin{array}{l}\text { Est. } 55 \\
\text { M 131 } \\
\text { "Iguatemy" }\end{array}$ & $17 / 6 / 56$ & $\begin{array}{l}24050^{\prime} \mathrm{S} \\
46^{\circ} 20^{\prime} \mathrm{W}\end{array}$ & 54 & $\begin{array}{c}10 \mathrm{~m} \text { de } \\
\text { cabo }\end{array}$ & 19.80 & 35.57 & 1900 & - & Standard \\
\hline $\begin{array}{l}\text { Est. } 56 \\
\text { M 132-33 } \\
\text { "Iguatemy" }\end{array}$ & $17 / 6 / 56$ & $\begin{array}{l}24036^{\prime} \mathrm{S} \\
46^{\circ} 10^{\prime} \mathrm{W}\end{array}$ & 48 & $\begin{array}{c}10 \mathrm{~m} \text { de } \\
\text { cabo }\end{array}$ & 20.50 & 35.89 & 2055 & - & Standard \\
\hline $\begin{array}{l}\text { Est. } 57 \\
\text { M 134-35 } \\
\text { "Iguatemy" }\end{array}$ & $17 / 6 / 56$ & $\begin{array}{l}24022^{\prime} \mathrm{S} \\
45^{\circ} 59^{\prime} \mathrm{W}\end{array}$ & 41 & $\begin{array}{c}10 \mathrm{~m} \text { de } \\
\text { cabo }\end{array}$ & 20.58 & 35.83 & 2300 & - & Standard \\
\hline $\begin{array}{l}\text { Est. } 60 \\
\text { M } 136-37 \\
\text { "Solimões" } \\
\end{array}$ & $31 / 10 / 56$ & $\begin{array}{l}24028.5 ' \mathrm{~S} \\
45046^{\prime} \mathrm{W}\end{array}$ & 62 & $\underset{\text { cabo }}{20 \mathrm{~m} \text { de }}$ & $\begin{array}{l}22.04 \\
21.32\end{array}$ & $\begin{array}{l}35.38 \\
35.40\end{array}$ & 1435 & 10 & Standard \\
\hline $\begin{array}{l}\text { Est. 61 } \\
\text { M 138 } \\
\text { "Solimões" }\end{array}$ & $31 / 10 / 56$ & $\begin{array}{l}2405 I^{\prime} \mathrm{S} \\
45^{\circ} 24^{\prime} \mathrm{W}\end{array}$ & 90 & $\begin{array}{c}50 \mathrm{~m} \text { de } \\
\text { cabo }\end{array}$ & $\begin{array}{l}22.00 \\
14.37\end{array}$ & $\begin{array}{l}35.40 \\
35.37\end{array}$ & 1740 & 20 & Standard \\
\hline $\begin{array}{l}\text { Est. 62 } \\
\text { M 139 } \\
\text { "Solimões" }\end{array}$ & $31 / 10 / 56$ & $\begin{array}{l}25^{\circ} 05^{\prime} \mathrm{S} \\
45^{\circ} 03 \mathrm{~W}\end{array}$ & 158 & $\begin{array}{c}50 \mathrm{~m} \mathrm{de} \\
\text { cabo }\end{array}$ & $\begin{array}{l}23.38 \\
22.82\end{array}$ & $\begin{array}{l}36.99 \\
36.89\end{array}$ & 2115 & 20 & Standard \\
\hline $\begin{array}{l}\text { Est. } 63 \\
\text { M } 140 \\
\text { "Solimões" } \\
\end{array}$ & $1 / 11 / 56$ & $\begin{array}{l}25011^{\prime} \mathrm{S} \\
45^{\circ} 01^{\prime} \mathrm{W}\end{array}$ & 1.900 & $\begin{array}{c}50 \mathrm{~m} \mathrm{de} \\
\text { cabo }\end{array}$ & $\begin{array}{l}22.70 \\
22.07\end{array}$ & $\begin{array}{l}36.84 \\
36.76\end{array}$ & 0131 & 20 & Apstein \\
\hline $\begin{array}{l}\text { Est. } 64 \\
\text { M } 141 \\
\text { "Solimões" } \\
\end{array}$ & $1 / 11 / 56$ & $\begin{array}{l}26008^{\prime} \mathrm{S} \\
43^{\circ} 58^{\prime} \mathrm{SW}\end{array}$ & 2.200 & $\begin{array}{c}50 \mathrm{~m} \text { de } \\
\text { cabo }\end{array}$ & $\begin{array}{l}22.30 \\
22.26\end{array}$ & $\begin{array}{l}36.76 \\
36.83\end{array}$ & 0645 & 20 & Apstein \\
\hline $\begin{array}{l}\text { Est. } 66 \\
\text { M } 142 \\
\text { "Solimö̉es" }\end{array}$ & $1 / 11 / 56$ & $\begin{array}{l}27012.2^{\prime} \mathrm{S} \\
42^{\circ} 29.8^{\prime} \mathrm{W}\end{array}$ & 2.130 & $\begin{array}{c}25 \mathrm{~m} \mathrm{de} \\
\text { cabo }\end{array}$ & $\begin{array}{l}21.14 \\
21.98\end{array}$ & $\begin{array}{l}36.81 \\
36.83\end{array}$ & 2115 & 20 & Standard \\
\hline $\begin{array}{l}\text { Est. 67 } \\
\text { M 143 } \\
\text { "Solimöes" }\end{array}$ & $2 / 11 / 56$ & $\begin{array}{l}27018.5 ' \mathrm{~S} \\
43038^{\prime} \mathrm{W}\end{array}$ & - & $\begin{array}{c}25 \mathrm{~m} \text { de } \\
\text { cabo }\end{array}$ & $\begin{array}{r}21.25 \\
21.87\end{array}$ & $\begin{array}{l}36.92 \\
36.86\end{array}$ & 0330 & 20 & Standard \\
\hline $\begin{array}{l}\text { Est. } 68 \\
\text { M } 144 \\
\text { "Solimöes" } \\
\end{array}$ & $2 / 11 / 56$ & $\begin{array}{l}27019^{\prime} \mathrm{S} \\
44^{\circ} 28^{\prime} \mathrm{W}\end{array}$ & - & $\begin{array}{c}50 \mathrm{~m} \mathrm{de} \\
\text { cabo }\end{array}$ & $\begin{array}{l}21.20 \\
21.16\end{array}$ & $\begin{array}{l}36.65 \\
36.54\end{array}$ & 0900 & 25 & Standard \\
\hline $\begin{array}{l}\text { Est. } 69 \\
\text { M 145 } \\
\text { "Solimöes" }\end{array}$ & $2 / 11 / 56$ & $\begin{array}{l}27010^{\prime} \mathrm{S} \\
45^{\circ} 27^{\prime} \mathrm{W}\end{array}$ & 2.200 & $\begin{array}{c}50 \mathrm{~m} \text { de } \\
\text { cabo }\end{array}$ & $\begin{array}{l}22.00 \\
21.48\end{array}$ & $\begin{array}{l}36.73 \\
36.64\end{array}$ & 1400 & 20 & Standard \\
\hline $\begin{array}{l}\text { Est. } 70 \\
\text { M 146 } \\
\text { "Solimöes" }\end{array}$ & $2 / 11 / 56$ & $\begin{array}{l}27018.2 \text { 'S } \\
46012 \text { 'SW }\end{array}$ & 1.000 & superf. & 21.08 & 36.72 & 2135 & 20 & Standard \\
\hline $\begin{array}{l}\text { Est. 71 } \\
\text { M 147 } \\
\text { "Solimões" }\end{array}$ & $3 / 11 / 56$ & $\begin{array}{l}27009^{\prime} \mathrm{S} \\
466^{\circ} \mathrm{W}\end{array}$ & 767 & superf. & 20.45 & 36.79 & 0215 & 20 & Standard \\
\hline
\end{tabular}




\begin{tabular}{|c|c|c|c|c|c|c|c|c|c|c|c|}
\hline & & & S A G & T T A & & & & PTEROS. & KROHN. & Total & \\
\hline bip. & enfl. & frid. & glor. & hex. & hisp. & $\min$. & serrat. & draco & pacifica & $\begin{array}{l}\text { indiv. } \\
\text { jovens }\end{array}$ & TOTAL \\
\hline $3.50 \%$ & $\begin{array}{c}364 \\
60.67 \%\end{array}$ & - & - & - & $\begin{array}{c}4 \\
0.66 \%\end{array}$ & $\begin{array}{c}58 \\
9.67 \%\end{array}$ & $\begin{array}{c}143 \\
23.83 \%\end{array}$ & $\begin{array}{c}28 \\
4.67 \%\end{array}$ & - & - & 600 \\
\hline - & $\begin{array}{l}11 \\
78.57 \%\end{array}$ & - & - & - & $21.43 \%$ & -- & - & - & - & - & 14 \\
\hline $2.17 \%$ & $\begin{array}{c}872 \\
76.09 \%\end{array}$ & $\begin{array}{c}2 \\
0.17 \%\end{array}$ & - & - & $\begin{array}{c}35 \\
3.05 \%\end{array}$ & $12 \%$ & $\begin{array}{c}216 \\
18.85 \%\end{array}$ & $\begin{array}{c}7 \\
0.61 \%\end{array}$ & - & - & 1.146 \\
\hline- & $\begin{array}{c}619 \\
54.39 \%\end{array}$ & - & - & - & $\begin{array}{c}23 \\
2.02 \%\end{array}$ & - & $\begin{array}{c}276 \\
24.25 \%\end{array}$ & - & - & $\begin{array}{c}220 \\
19.33 \%\end{array}$ & 1.138 \\
\hline $3.81 \%$ & $\begin{array}{c}850 \\
86.46 \%\end{array}$ & - & - & - & $\begin{array}{c}27 \\
2.74 \%\end{array}$ & $\begin{array}{c}43 \\
4.37 \%\end{array}$ & $0.81 \%$ & $\begin{array}{c}6 \\
0.61 \%\end{array}$ & - & $4.17 \%$ & 983 \\
\hline- & $\begin{array}{c}700 \\
89.97 \%\end{array}$ & - & - & - & $\begin{array}{c}19 \\
2.44 \%\end{array}$ & $\begin{array}{c}19 \\
2.44 \%\end{array}$ & $\begin{array}{c}16 \\
2.05 \%\end{array}$ & $\begin{array}{c}3 \\
0.38 \%\end{array}$ & $0.12 \%$ & $\begin{array}{c}20 \\
2.57 \%\end{array}$ & 778 \\
\hline $3.14 \%$ & $\begin{array}{c}578 \\
82.80 \%\end{array}$ & - & - & - & $\begin{array}{c}24 \\
3.43 \%\end{array}$ & $\begin{array}{c}68 \\
9.74 \%\end{array}$ & $\begin{array}{c}9 \\
1.14 \%\end{array}$ & $0.43 \%$ & - & $2.15 \%$ & 698 \\
\hline $2.27 \%$ & $\begin{array}{c}612 \\
84.18 \%\end{array}$ & $\begin{array}{c}34 \\
4.67 \%\end{array}$ & $\stackrel{3}{0.41 \%}$ & - & $1.51 \%$ & $\begin{array}{c}52 \\
7.15 \%\end{array}$ & $\begin{array}{c}7 \\
0.96 \%\end{array}$ & - & - & $\begin{array}{c}6 \\
0.82 \%\end{array}$ & $72 \%$ \\
\hline- & $\begin{array}{c}138 \\
80.70 \%\end{array}$ & $2.33 \%$ & $0.58 \%$ & - & $2.92 \%$ & $\begin{array}{c}20 \\
11.69 \%\end{array}$ & - & - & - & $1.77 \%$ & 171 \\
\hline - & $\begin{array}{c}741 \\
81.33 \%\end{array}$ & $\begin{array}{c}56 \\
6.14 \%\end{array}$ & - & - & $\begin{array}{c}53 \\
5.81 \%\end{array}$ & $\begin{array}{c}54 \\
5.92 \%\end{array}$ & - & $0.10 \%$ & - & $\begin{array}{c}6 \\
0.66 \%\end{array}$ & 911 \\
\hline - & $\begin{array}{c}1.153 \\
89.31 \%\end{array}$ & $\begin{array}{c}15 \\
1.16 \%\end{array}$ & - & - & $\begin{array}{c}12 \\
0.92 \%\end{array}$ & $\begin{array}{c}105 \\
8.05 \%\end{array}$ & - & -- & - & $0.46 \%$ & 1.291 \\
\hline - & $\begin{array}{c}10 \\
20.00 \%\end{array}$ & - & - & - & $\stackrel{8}{8}$ & - & $\begin{array}{c}10 \\
20.00 \%\end{array}$ & - & - & $\begin{array}{c}22 \\
44.00 \%\end{array}$ & 50 \\
\hline $\begin{array}{l}76 \\
61.79 \%\end{array}$ & $\begin{array}{c}31 \\
25.20 \%\end{array}$ & $0.81 \%$ & $0.81 \%$ & $0.81 \%$ & - & - & $\begin{array}{c}4 \\
3.25 \%\end{array}$ & - & - & $7.32 \%$ & 123 \\
\hline- & $\frac{9}{10.34 \%}$ & - & $\begin{array}{c}3 \\
3.45 \%\end{array}$ & - & $2.30 \%$ & - & $\begin{array}{c}71 \\
81.61 \%\end{array}$ & - & - & $2.30 \%$ & 87 \\
\hline $\begin{array}{c}2 \\
10.53 \%\end{array}$ & - & - & - & - & - & - & $\frac{12}{63.15 \%}$ & - & - & $\begin{array}{c}5 \\
26.32 \%\end{array}$ & 19 \\
\hline- & - & - & - & - & - & - & 50.5 & - & - & $50.00 \%$ & 10 \\
\hline $3.65 \%$ & $\begin{array}{c}12 \\
6.09 \%\end{array}$ & - & $\begin{array}{c}25 \\
12.69 \%\end{array}$ & - & $\begin{array}{c}2 \\
1.01 \%\end{array}$ & - & $\begin{array}{c}146 \\
74.11 \%\end{array}$ & $\begin{array}{c}5 \\
2.54 \%\end{array}$ & - & $0.51 \%$ & 197 \\
\hline- & $13.26 \%$ & - & $\begin{array}{c}23 \\
23.47 \%\end{array}$ & $\frac{1}{1.02 \%}$ & - & - & $\begin{array}{c}50 \\
51.02 \%\end{array}$ & $1.02 \%$ & - & $\begin{array}{c}10 \\
10.20 \%\end{array}$ & 98 \\
\hline $0.64 \%$ & $3.83 \%$ & - & $\begin{array}{c}11 \\
3.51 \%\end{array}$ & $0.96 \%$ & - & $\begin{array}{c}2 \\
0.64 \%\end{array}$ & $\begin{array}{c}178 \\
56.87 \%\end{array}$ & $\begin{array}{c}2 \\
0.64 \%\end{array}$ & - & $\begin{array}{c}103 \\
32.91 \%\end{array}$ & 313 \\
\hline - & - & - & $0.70 \%$ & $\frac{11}{7.74 \%}$ & $1.41 \%$ & - & $\begin{array}{c}67 \\
47.18 \%\end{array}$ & $15.49 \%$ & - & $\begin{array}{c}39 \\
27.46 \%\end{array}$ & 142 \\
\hline - & - & - & - & -- & - & - & $\begin{array}{c}10 \\
58.82 \%\end{array}$ & $\begin{array}{c}6 \\
35.29 \%\end{array}$ & - & $5.88 \%$ & 17 \\
\hline $2.22 \%$ & $\begin{array}{c}20 \\
44.44 \%\end{array}$ & - & - & $\frac{1}{2.22 \%}$ & - & - & $\begin{array}{c}20 \\
44.44 \%\end{array}$ & - & - & $\begin{array}{c}3 \\
6.67 \%\end{array}$ & 45 \\
\hline
\end{tabular}




\begin{tabular}{|c|c|c|c|c|c|c|c|c|c|}
\hline Amostra & Data & Posição & $\begin{array}{l}\text { Prof. } \\
\text { local } \\
\text { (m) }\end{array}$ & $\begin{array}{l}\text { Prof. da } \\
\text { coleta } \\
\text { (m) }\end{array}$ & Temp. & $\begin{array}{c}\text { Salin. } \\
0 / 00\end{array}$ & Hora & $\begin{array}{l}\text { Duração } \\
\text { do lance } \\
\text { (min.) }\end{array}$ & $\begin{array}{c}\text { Tipo } \\
\text { de rêde }\end{array}$ \\
\hline $\begin{array}{l}\text { Est. } 72 \\
\text { M } 148 \\
\text { "Solimões" }\end{array}$ & $3 / 11 / 56$ & $\begin{array}{l}27013^{\prime} \mathrm{S} \\
47008^{\prime} \mathrm{W}\end{array}$ & 213 & $\begin{array}{c}50 \mathrm{~m} \text { de } \\
\text { cabo }\end{array}$ & $\begin{array}{l}20.71 \\
21.02\end{array}$ & $\begin{array}{l}36.05 \\
36.09\end{array}$ & 0640 & 20 & Standard \\
\hline $\begin{array}{l}\text { Est. } 73 \\
\text { M } 149 \\
\text { "Solimões" }\end{array}$ & $3 / 11 / 56$ & $\begin{array}{l}27018.2^{\prime} \mathrm{S} \\
47031^{\prime} \mathrm{W}\end{array}$ & 135 & $\begin{array}{c}50 \mathrm{~m} \text { de } \\
\text { cabo }\end{array}$ & $\begin{array}{l}21.20 \\
21.10\end{array}$ & $\begin{array}{l}35.54 \\
35.60\end{array}$ & 1100 & 20 & Standard \\
\hline $\begin{array}{l}\text { Est. 74 } \\
\text { M 150 } \\
\text { "Solimões" }\end{array}$ & $3 / 11 / 56$ & $\begin{array}{l}27017^{\prime} \mathrm{S} \\
47054.5^{\prime} \mathrm{W}\end{array}$ & 70 & $\begin{array}{c}50 \mathrm{~m} \text { de } \\
\text { cabo }\end{array}$ & $\begin{array}{l}21.40 \\
20.96\end{array}$ & $\begin{array}{l}35.54 \\
35.53\end{array}$ & 1245 & 20 & Standard \\
\hline $\begin{array}{l}\text { Est. } 75 \\
\text { M 151 } \\
\text { "Solimões" }\end{array}$ & $5 / 11 / 56$ & $\begin{array}{l}28000^{\prime} \mathrm{S} \\
482^{\prime} 2^{\prime} \mathrm{W}\end{array}$ & 58 & $\begin{array}{c}50 \mathrm{~m} \mathrm{de} \\
\text { cabo }\end{array}$ & $\begin{array}{l}20.40 \\
18.91\end{array}$ & $\begin{array}{l}35.16 \\
35.22\end{array}$ & 1810 & 20 & Standard \\
\hline $\begin{array}{l}\text { Est. } 75 \\
\text { M } 152 \\
\text { "Solimões" } \\
\end{array}$ & $5 / 11 / 56$ & $\begin{array}{l}28000^{\prime} \mathrm{S} \\
482^{\circ} \mathrm{W}\end{array}$ & 58 & $\begin{array}{c}50 \mathrm{~m} \text { de } \\
\text { cabo }\end{array}$ & $\begin{array}{l}20.40 \\
18.91\end{array}$ & $\begin{array}{l}35.16 \\
35.22\end{array}$ & 1810 & 20 & Standard \\
\hline $\begin{array}{l}\text { Est. } 76 \\
\text { M } 153 \\
\text { "Solimões" }\end{array}$ & $5 / 11 / 56$ & $\begin{array}{l}28024^{\prime} \mathrm{S} \\
48030.2^{\prime} \mathrm{W}\end{array}$ & 62 & $\begin{array}{c}62 \mathrm{~m} \text { de } \\
\text { cabo }\end{array}$ & $\begin{array}{l}19.37 \\
16.48\end{array}$ & $\begin{array}{l}35.40 \\
35.64\end{array}$ & 2100 & 20 & Standard \\
\hline $\begin{array}{l}\text { Est. } 77 \\
\text { M. } 154 \\
\text { "Solimões" }\end{array}$ & $5 / 11 / 56$ & $\begin{array}{l}28047.3^{\prime} \mathrm{S} \\
48038.2^{\prime} \mathrm{W}\end{array}$ & 80 & $\begin{array}{c}25 \mathrm{~m} \text { de } \\
\text { cabo }\end{array}$ & $\begin{array}{l}20.61 \\
20.84\end{array}$ & $\begin{array}{l}35.65 \\
35.52\end{array}$ & 2300 & 20 & Standard \\
\hline $\begin{array}{l}\text { Est. } 78 \\
\text { M } 155 \\
\text { "Solimões" }\end{array}$ & $6 / 11 / 56$ & $\begin{array}{l}290^{\circ} 8^{\prime} \mathrm{S} \\
49^{\circ} 3^{\prime} \mathrm{W}\end{array}$ & 60 & superf. & 19.02 & 35.52 & 0155 & 20 & Standard \\
\hline $\begin{array}{l}\text { Est. } 79 \\
\text { M } 156 \\
\text { "Solimões" }\end{array}$ & $6 / 11 / 56$ & $\begin{array}{l}290^{\circ} 7^{\prime} \mathrm{S} \\
49038^{\prime} \mathrm{W}\end{array}$ & 45 & superf. & 19.46 & 35.53 & 0405 & 20 & Standard \\
\hline $\begin{array}{l}\text { Est. } 80 \\
\text { M } 157 \\
\text { "Solimöes" }\end{array}$ & $6 / 11 / 56$ & $\begin{array}{l}29043^{\prime} \mathrm{S} \\
49006^{\prime} \mathrm{W}\end{array}$ & 98 & $\begin{array}{c}50 \mathrm{~m} \text { de } \\
\text { cabo }\end{array}$ & $\begin{array}{l}20.68 \\
20.72\end{array}$ & $\begin{array}{l}35.24 \\
35.22\end{array}$ & 0645 & 20 & Standard \\
\hline $\begin{array}{l}\text { Est. } 81 \\
\text { M. } 158 \\
\text { "Solimões" }\end{array}$ & $6 / 11 / 56$ & $\begin{array}{l}30002^{\prime} \mathrm{S} \\
48039^{\prime} \mathrm{W}\end{array}$ & 148 & $\begin{array}{c}50 \mathrm{~m} \mathrm{de} \\
\text { cabo }\end{array}$ & $\begin{array}{l}20.76 \\
20.53\end{array}$ & $\begin{array}{l}35.11 \\
35.08\end{array}$ & 0930 & 20 & Standard \\
\hline $\begin{array}{l}\text { Est. } 82 \\
\text { M } 159 \\
\text { "Solimöes" }\end{array}$ & $6 / 11 / 56$ & $\begin{array}{l}30^{\circ} 25^{\prime} \mathrm{S} \\
480^{\prime} \mathrm{W}\end{array}$ & 615 & $\begin{array}{c}60 \mathrm{~m} \text { de } \\
\text { cabo }\end{array}$ & $\begin{array}{l}20.91 \\
21.30\end{array}$ & $\begin{array}{l}35.43 \\
36.79\end{array}$ & 1320 & 20 & Standard \\
\hline $\begin{array}{l}\text { Est. } 83 \\
\text { M } 160 \\
\text { "Solimöes" }\end{array}$ & $6 / 11 / 56$ & $\begin{array}{l}30055^{\prime} \mathrm{S} \\
470^{\prime} 5^{\prime} \mathrm{W}\end{array}$ & 1.600 & $\begin{array}{c}50 \mathrm{~m} \mathrm{de} \\
\text { cabo }\end{array}$ & $\begin{array}{l}19.73 \\
19.64\end{array}$ & $\begin{array}{l}36.46 \\
36.48\end{array}$ & 1915 & 20 & Standard \\
\hline $\begin{array}{l}\text { Est. } 84 \\
\text { M 161 } \\
\text { "Solimöes" }\end{array}$ & $6 / 11 / 56$ & $\begin{array}{l}310311^{\prime} \mathrm{S} \\
46033^{\prime} \mathrm{W}\end{array}$ & 3.000 & $\begin{array}{c}50 \mathrm{~m} \mathrm{de} \\
\text { cabo }\end{array}$ & $\begin{array}{l}18.18 \\
17.82\end{array}$ & $\begin{array}{l}36.21 \\
36.10\end{array}$ & 2350 & 20 & Standard \\
\hline $\begin{array}{l}\text { Est. } 85 \\
\text { M. } 162 \\
\text { "Solimões" } \\
\end{array}$ & $7 / 11 / 56$ & $\begin{array}{l}31057^{\prime} \mathrm{S} \\
45^{\circ} 45^{\prime} \mathrm{W}\end{array}$ & 3.800 & $\begin{array}{c}50 \mathrm{~m} \text { de } \\
\text { cabo }\end{array}$ & $\begin{array}{l}18.10 \\
17.76\end{array}$ & $\begin{array}{l}36.19 \\
36.19\end{array}$ & 0440 & 20 & Standard \\
\hline $\begin{array}{l}\text { Est. } 86 \\
\text { M } 163 \\
\text { "Solimões" }\end{array}$ & $7 / 11 / 56$ & $\begin{array}{l}320^{\circ} 24^{\prime} \mathrm{S} \\
44054^{\prime} \mathrm{W}\end{array}$ & 3.800 & $\begin{array}{c}50 \mathrm{~m} \text { de } \\
\text { cabo }\end{array}$ & $\begin{array}{l}18.90 \\
18.63\end{array}$ & $\begin{array}{l}36.27 \\
36.28\end{array}$ & 0440 & 20 & Standard \\
\hline $\begin{array}{l}\text { Est. } 87 \\
\text { M 164 } \\
\text { "Solimões" }\end{array}$ & $7 / 11 / 56$ & $\begin{array}{l}33012^{\prime} \mathrm{S} \\
45040^{\prime} \mathrm{W}\end{array}$ & - & $\begin{array}{c}50 \mathrm{~m} \text { de } \\
\text { cabo }\end{array}$ & $\begin{array}{l}20.19 \\
18.28\end{array}$ & $\begin{array}{l}36.24 \\
36.26\end{array}$ & 1405 & 20 & Standard \\
\hline $\begin{array}{l}\text { Est. } 88 \\
\text { M i65 } \\
\text { "Solimões" }\end{array}$ & $7 / 11 / 56$ & $\begin{array}{l}340^{\circ} 00^{\prime} \mathrm{S} \\
46012^{\prime} \mathrm{W}\end{array}$ & - & $\begin{array}{c}25 \mathrm{~m} \mathrm{de} \\
\text { cabo }\end{array}$ & $\begin{array}{l}18.90 \\
18.36\end{array}$ & $\begin{array}{l}36.12 \\
36.18\end{array}$ & 1850 & 20 & Standard \\
\hline $\begin{array}{l}\text { Est. } 89 \\
\text { M } 166 \\
\text { "Solimöes" }\end{array}$ & $7 / 11 / 56$ & $\begin{array}{l}34042^{\prime} \mathrm{S} \\
46045^{\prime} \mathrm{W}\end{array}$ & 4.500 & $\begin{array}{c}25 \mathrm{~m} \mathrm{de} \\
\text { cabo }\end{array}$ & $\begin{array}{l}18.44 \\
18.18\end{array}$ & $\begin{array}{l}36.23 \\
36.29\end{array}$ & 2320 & 20 & Standard \\
\hline $\begin{array}{l}\text { Est. } 90 \\
\text { M } 167 \\
\text { "Solimöes" }\end{array}$ & $8 / 11 / 56$ & $\begin{array}{l}35018^{\prime} \mathrm{S} \\
47012^{\prime} \mathrm{W}\end{array}$ & - & $\underset{\text { cabo }}{25 \mathrm{~m} d e}$ & $\begin{array}{l}18.40 \\
18.24\end{array}$ & $\begin{array}{l}35.89 \\
36.04\end{array}$ & 0345 & 20 & Standard \\
\hline $\begin{array}{l}\text { Est. } 91 \\
\text { M } 168 \\
\text { "Solimöes" } \\
\end{array}$ & $8 / 11 / 56$ & $\begin{array}{l}34050^{\prime} \mathrm{S} \\
47052^{\prime} \mathrm{W}\end{array}$ & - & $\begin{array}{c}50 \mathrm{~m} \mathrm{de} \\
\text { cabo }\end{array}$ & $\begin{array}{l}19.40 \\
17.43\end{array}$ & $\begin{array}{l}36.02 \\
36.18\end{array}$ & 1030 & 20 & Standard \\
\hline $\begin{array}{l}\text { Est. } 92 \\
\text { M } 169 \\
\text { "Solimöes" }\end{array}$ & $8 / 11 / 56$ & $\begin{array}{l}340^{\circ} 15^{\prime} \mathrm{S} \\
48^{\circ} 40^{\prime} \mathrm{W}\end{array}$ & 4.000 & $\underset{\text { cabo }}{50 \mathrm{~m} \text { de }}$ & $\begin{array}{l}18.19 \\
17.54\end{array}$ & $\begin{array}{l}36.04 \\
36.03\end{array}$ & 1700 & 20 & Standerd \\
\hline
\end{tabular}




\begin{tabular}{|c|c|c|c|c|c|c|c|c|c|c|c|}
\hline bip. & enfl. & frid. & $\begin{array}{l}\mathbf{S} \bar{A} \mathbf{G} \\
\text { glor. }\end{array}$ & $\begin{array}{l}\text { I T T } \\
\text { hex. }\end{array}$ & hisp. & $\min$. & serrat. & $\begin{array}{c}\text { PTEROS. } \\
\text { draco }\end{array}$ & $\begin{array}{l}\text { KROHN. } \\
\text { pacifica }\end{array}$ & $\begin{array}{l}\text { Total } \\
\text { indiv. } \\
\text { jovens }\end{array}$ & TOTAL \\
\hline- & $\begin{array}{c}261 \\
44.00 \%\end{array}$ & - & - & $\begin{array}{c}2 \\
0.34 \%\end{array}$ & $\begin{array}{c}16 \\
2.70 \%\end{array}$ & - & $\begin{array}{l}310 \\
52.28 \%\end{array}$ & $\stackrel{2}{2} \%$ & - & $0.34 \%$ & 593 \\
\hline - & $\begin{array}{c}2.942 \\
96.78 \%\end{array}$ & - & - & - & $\begin{array}{c}39 \\
1.28 \%\end{array}$ & - & $\begin{array}{c}58 \\
1.91 \%\end{array}$ & $0.03 \%$ & - & - & 3.040 \\
\hline - & $\begin{array}{c}2.829 \\
92.97 \%\end{array}$ & - & $0.03 \%$ & $0.39 \%$ & $\begin{array}{c}31 \\
1.02 \%\end{array}$ & $\begin{array}{r}164 \\
5.39 \%\end{array}$ & $\begin{array}{c}5 \\
0.16 \%\end{array}$ & $0.03 \%$ & - & 一 & 3.043 \\
\hline- & $\begin{array}{c}94 \\
81.73 \%\end{array}$ & - & - & - & $\begin{array}{c}11 \\
9.58 \%\end{array}$ & - & - & - & - & $\begin{array}{c}10 \\
8.69 \%\end{array}$ & 115 \\
\hline- & $\begin{array}{c}135 \\
61.63 \%\end{array}$ & $\begin{array}{c}5 \\
2.27 \%\end{array}$ & - & - & $\begin{array}{c}75 \\
34.09 \%\end{array}$ & $\begin{array}{c}4 \\
1.82 \%\end{array}$ & $0.45 \%$ & - & - & - & 220 \\
\hline - & $\begin{array}{c}579 \\
89.35 \%\end{array}$ & - & - & - & - & - & $\begin{array}{c}61 \\
9.41 \%\end{array}$ & - & - & $1.23 \%$ & 648 \\
\hline - & $\begin{array}{c}424 \\
87.78 \%\end{array}$ & - & - & - & $\begin{array}{c}10 \\
2.07 \%\end{array}$ & - & $10.14 \%$ & - & - & - & 483 \\
\hline - & $\begin{array}{c}238 \\
75.07 \%\end{array}$ & $\begin{array}{c}13 \\
4.10 \%\end{array}$ & - & - & $\begin{array}{c}18 \\
5.67 \%\end{array}$ & $\begin{array}{c}6 \\
1.89 \%\end{array}$ & - & - & 一 & $13.24 \%$ & 317 \\
\hline- & $\begin{array}{c}198 \\
76.44 \%\end{array}$ & $0.38 \%$ & - & - & $\begin{array}{c}40 \\
15.44 \%\end{array}$ & - & - & - & - & $\begin{array}{c}20 \\
7.72 \%\end{array}$ & 259 \\
\hline - & $\begin{array}{c}1.174 \\
90.30 \%\end{array}$ & - & - & - & $\begin{array}{c}22 \\
1.69 \%\end{array}$ & 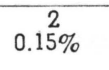 & $\begin{array}{c}95 \\
7.31 \%\end{array}$ & - & - & $\begin{array}{c}7 \\
0.54 \%\end{array}$ & 1.300 \\
\hline - & $\begin{array}{c}554 \\
77.92 \%\end{array}$ & - & - & - & $0.42 \%$ & - & $\begin{array}{r}154 \\
21.66 \%\end{array}$ & - & 一 & - & 711 \\
\hline- & $\begin{array}{c}239 \\
45.09 \%\end{array}$ & - & - & $\begin{array}{c}3 \\
0.57 \%\end{array}$ & $\begin{array}{c}5 \\
0.94 \%\end{array}$ & $\begin{array}{c}73 \\
13.77 \%\end{array}$ & $\begin{array}{c}201 \\
37.92 \%\end{array}$ & $1.70 \%$ & - & - & 530 \\
\hline - & $\begin{array}{c}2 \\
0.25 \%\end{array}$ & 一 & - & $0.38 \%$ & - & - & $\begin{array}{r}772 \\
98.34 \%\end{array}$ & $1.02 \%$ & - & - & 785 \\
\hline $\begin{array}{c}6 \\
1.34 \%\end{array}$ & - & - & - & - & 一 & 一 & $\begin{array}{r}321 \\
98.16 \%\end{array}$ & - & - & - & 327 \\
\hline $0.68 \%$ & - & - & - & - & - & - & $\begin{array}{c}290 \\
99.32 \%\end{array}$ & - & - & - & 292 \\
\hline $0.29 \%$ & $\therefore \quad-$ & - & - & $0.19 \%$ & 一 & - & $\begin{array}{c}1.024 \\
99.42 \%\end{array}$ & $0.10 \%$ & - & - & 1.030 \\
\hline $1.80 \%$ & $\begin{array}{c}20 \\
5.15 \%\end{array}$ & 一 & - & - & - & 一 & $\begin{array}{c}355 \\
91.49 \%\end{array}$ & $\begin{array}{c}6 \\
1.55 \%\end{array}$ & - & - & 388 \\
\hline- & - & - & - & - & - & - & - & - & - & - & - \\
\hline - & 一 & 一 & - & - & - & - & $75.00 \%$ & $12.50 \%$ & - & $12.50 \%$ & 8 \\
\hline - & 一 & - & 一 & - & 一 & - & $100.00 \%$ & - & - & - & 8 \\
\hline - & - & - & - & - & - & - & - & - & - & - & - \\
\hline- & - & - & - & - & - & - & - & - & - & - & - \\
\hline
\end{tabular}




\begin{tabular}{|c|c|c|c|c|c|c|c|c|c|}
\hline Amostra & Date & Posição & $\begin{array}{l}\text { Prof. } \\
\text { local } \\
\text { (m) }\end{array}$ & $\begin{array}{l}\text { Prof. da } \\
\text { coleta } \\
\text { (m) }\end{array}$ & Temp. & Salin. & Hora & $\begin{array}{l}\text { Duraçāo } \\
\text { do lance } \\
\text { (min.) }\end{array}$ & de rêpo \\
\hline $\begin{array}{l}\text { Est. } 93 \\
\text { M } 170 \\
\text { "Solimöes" }\end{array}$ & $8 / 11 / 56$ & $\begin{array}{l}33045^{\prime} \mathrm{S} \\
49029^{\prime} \mathrm{W}\end{array}$ & - & $\begin{array}{l}25 \mathrm{~m} \text { de } \\
\text { cabo }\end{array}$ & $\begin{array}{l}18.90 \\
18.47\end{array}$ & $\begin{array}{l}35.62 \\
35.99\end{array}$ & 2240 & 20 & Standard \\
\hline $\begin{array}{l}\text { Est. 94 } \\
\text { M 171 } \\
\text { "Solimöes" }\end{array}$ & $9 / 11 / 56$ & $\begin{array}{l}33018^{\prime} \mathrm{S} \\
50018^{\prime} \mathrm{W}\end{array}$ & 1.000 & $\begin{array}{c}25 \mathrm{~m} \text { de } \\
\text { cabo }\end{array}$ & 19.94 & 35.25 & 0305 & 20 & Standard \\
\hline $\begin{array}{l}\text { Est. } 95 \\
\text { M 172 } \\
\text { "Solimões" }\end{array}$ & $9 / 11 / 56$ & $\begin{array}{l}32^{\prime} 48^{\prime} \mathrm{S} \\
50^{\circ} 54.5^{\prime} \mathrm{W}\end{array}$ & 73 & $\begin{array}{c}25 \mathrm{~m} \mathrm{de} \\
\text { cabo }\end{array}$ & $\begin{array}{l}18.19 \\
19.13\end{array}$ & $\begin{array}{l}33.20 \\
33.17\end{array}$ & 0620 & 20 & Standard \\
\hline $\begin{array}{l}\text { Est. } 96 \\
\text { M } 173 \\
\text { "Solimőes" }\end{array}$ & $9 / 11 / 56$ & $\begin{array}{l}32030^{\prime} \mathrm{S} \\
513^{\circ} \mathrm{W}\end{array}$ & 58 & $\underset{\text { cabo }}{50 \mathrm{~m} \text { de }}$ & $\begin{array}{l}19.21 \\
18.28\end{array}$ & $\begin{array}{l}33.15 \\
34.04\end{array}$ & 0858 & 20 & Standard \\
\hline $\begin{array}{l}\text { Est. } 97 \\
\text { M } 174 \\
\text { "Solimöes" } \\
\end{array}$ & $9 / 11 / 56$ & $\begin{array}{l}320^{\circ} 0^{\prime} \mathrm{S} \\
51037^{\prime} \mathrm{W}\end{array}$ & 26 & $\begin{array}{c}25 \mathrm{~m} \mathrm{de} \\
\text { cabo }\end{array}$ & $\begin{array}{l}19.40 \\
17.81\end{array}$ & $\begin{array}{l}32.88 \\
34.54\end{array}$ & 1050 & 20 & Standard \\
\hline $\begin{array}{l}\text { Est. } 98 \\
\text { M } 175 \\
\text { "Solimões" }\end{array}$ & $9 / 11 / 56$ & $\begin{array}{l}32011 \text { 'S } \\
51045^{\prime} \mathrm{W}\end{array}$ & 19 & $\begin{array}{c}15 \mathrm{~m} \text { de } \\
\text { cabo }\end{array}$ & $\begin{array}{l}19.47 \\
18.79\end{array}$ & $\begin{array}{l}32.59 \\
33.54\end{array}$ & 1210 & 20 & Standard \\
\hline $\begin{array}{l}\text { Est. } 99 \\
\text { M 176 } \\
\text { "Solimões" }\end{array}$ & $11 / 11 / 56$ & $\begin{array}{l}31052^{\prime} \mathrm{S} \\
51023^{\prime} \mathrm{W}\end{array}$ & 25 & $\begin{array}{c}25 \mathrm{~m} \mathrm{de} \\
\text { cabo }\end{array}$ & $\begin{array}{l}22.13 \\
18.70\end{array}$ & $\begin{array}{l}32.16 \\
34.34\end{array}$ & 1400 & 10 & Standard \\
\hline $\begin{array}{l}\text { Est. } 105 \\
\text { M iT7 } \\
\text { "Solimöes" }\end{array}$ & $15 / 11 / 56$ & $\begin{array}{l}25049.1^{\prime} \mathrm{S} \\
40004^{\prime} \mathrm{W}\end{array}$ & 29 & $\underset{\text { cabo }}{25 \mathrm{~m} \mathrm{de}}$ & $\begin{array}{l}22.40 \\
22.26\end{array}$ & $\begin{array}{l}33.46 \\
33.50\end{array}$ & 0840 & 20 & Standard \\
\hline $\begin{array}{l}\text { Est. } 106 \\
\text { M } 178 \\
\text { "Solimões" }\end{array}$ & $15 / 11 / 56$ & $\begin{array}{l}260^{\circ} 98^{\prime} \mathrm{S} \\
47048^{\prime} \mathrm{W}\end{array}$ & 58 & $\begin{array}{c}50 \mathrm{~m} \mathrm{de} \\
\text { cabo }\end{array}$ & $\begin{array}{l}22.71 \\
21.86\end{array}$ & $\begin{array}{l}34.59 \\
35.45\end{array}$ & 1100 & 20 & Standard \\
\hline $\begin{array}{l}\text { Est. } 107 \\
\mathrm{M} 179 \\
\text { "Solimöes" }\end{array}$ & $15 / 11 / 56$ & $\begin{array}{l}26^{\circ} 25^{\prime} \mathrm{S} \\
47035^{\prime} \mathrm{W}\end{array}$ & 66 & superf. & 23.07 & 35.57 & 1305 & 10 & Standard \\
\hline $\begin{array}{l}\text { Est. } 107 \\
\text { M } 180 \\
\text { "Solimões" }\end{array}$ & $15 / 11 / 56$ & $\begin{array}{l}260^{\circ} 25^{\prime} \mathrm{S} \\
47035^{\prime} \mathrm{W}\end{array}$ & 66 & $\begin{array}{c}50 \mathrm{~m} \text { de } \\
\text { cabo }\end{array}$ & $\begin{array}{l}23.07 \\
21.92\end{array}$ & $\begin{array}{l}35.57 \\
35.56\end{array}$ & 1305 & 20 & Standard \\
\hline $\begin{array}{l}\text { Est. } 108 \\
\text { M } 181 \\
\text { "Solimões" }\end{array}$ & $15 / 11 / 56$ & $\begin{array}{l}25058^{\prime} \mathrm{S} \\
47012^{\prime} \mathrm{W}\end{array}$ & 73 & $\begin{array}{c}50 \mathrm{~m} \text { de } \\
\text { cabo }\end{array}$ & $\begin{array}{l}22.42 \\
21.78\end{array}$ & $\begin{array}{l}35.85 \\
35.86\end{array}$ & 1720 & 20 & Standard \\
\hline $\begin{array}{l}\text { Est. } 109 \\
\text { M 182 } \\
\text { "Solimöes" }\end{array}$ & $15 / 11 / 56$ & $\begin{array}{c}25^{\circ} 30^{\prime} \mathrm{S} \\
46^{\circ} 48^{\prime} \mathrm{W}\end{array}$ & 73 & $\begin{array}{c}25 \mathrm{~m} \mathrm{de} \\
\text { cabo }\end{array}$ & $\begin{array}{l}21.80 \\
21.74\end{array}$ & $\begin{array}{l}35.66 \\
35.58\end{array}$ & 2035 & 20 & Standard \\
\hline $\begin{array}{l}\text { Est. } 110 \\
\text { M } 183 \\
\text { "Solimöes" }\end{array}$ & $16 / 11 / 56$ & $\begin{array}{l}25001.8^{\prime} \mathrm{S} \\
46^{\circ} 24^{\prime} \mathrm{W}\end{array}$ & 63 & $\begin{array}{c}25 \mathrm{~m} \mathrm{de} \\
\text { cabo }\end{array}$ & $\begin{array}{l}22.00 \\
21.99\end{array}$ & $\begin{array}{l}35.56 \\
35.55\end{array}$ & 0015 & 20 & Standard \\
\hline $\begin{array}{l}\text { Est. 111 } \\
\text { M 184 } \\
\text { "Solimões" }\end{array}$ & $16 / 11 / 56$ & $\begin{array}{l}24039^{\prime} \mathrm{S} \\
46003^{\prime} \mathrm{W}\end{array}$ & 57 & $\begin{array}{c}25 \mathrm{~m} \text { de } \\
\text { cabo }\end{array}$ & $\begin{array}{l}22.03 \\
22.00\end{array}$ & $\begin{array}{c}35.44 \\
35.42\end{array}$ & 0300 & 20 & Standard \\
\hline $\begin{array}{l}\text { Est. } 112 \\
\text { M } 185 \\
\text { "Solimões" }\end{array}$ & $16 / 11 / 56$ & $\begin{array}{l}24024.5^{\prime} \mathrm{S} \\
45050^{\prime} \mathrm{W}\end{array}$ & 56 & $\begin{array}{c}25 \mathrm{~m} \text { de } \\
\text { cabo }\end{array}$ & $\begin{array}{l}21.80 \\
21.76\end{array}$ & $\begin{array}{l}35.49 \\
35.43\end{array}$ & 0445 & 20 & Standard \\
\hline
\end{tabular}




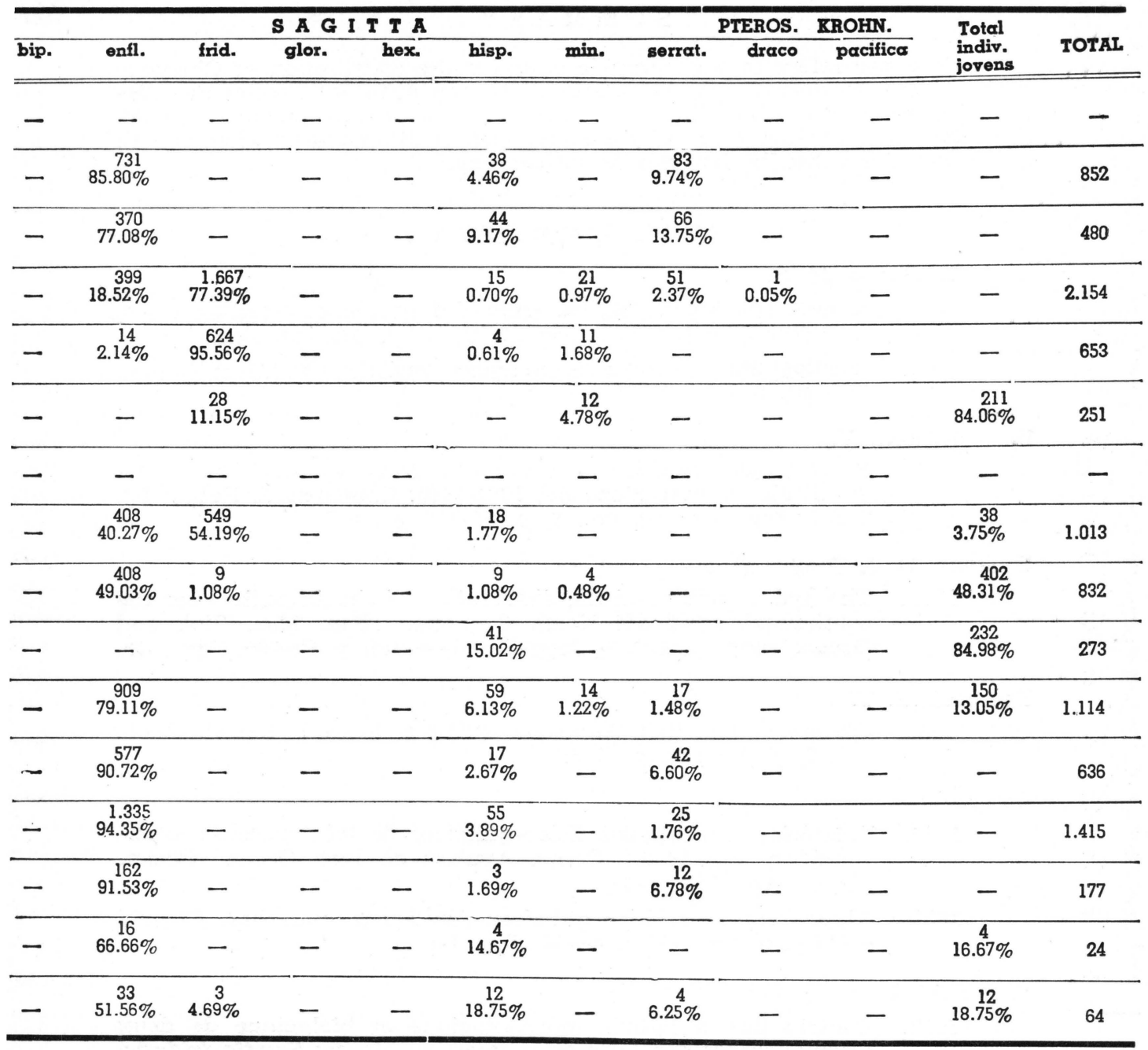




\section{S U M M A R Y}

This paper refers to a geographic study of the distribution of Chaetognatha in the Western South Atlantic and the ten different species are discussed in relation to different water masses. Samples were taken in coastal, shelf and tropical waters. Finally a correlation of the medusan, chaetognath and water mass distribution was tentatively made.

\section{B I B L I O G R A F I A}

Almetda Prado, M. S.

1960. A new species of Sagitta from the southern Brazilian coast. An. Acad. Bras. Ciênc., vol 32, n. ${ }^{\circ}$ 2, p. 275-280, figs. 1-5.

1961. Chaetognatha encontrados em águas brasileiras. Bol. Inst. Ocean., vol. XI, fasc. 2 , p. $31-55$, est. $1-2$.

BALDASSERONI, V.

1915. Raccolte planctoniche fatte dalla R. Nave Liguria" nel viaggio di circonnavigazione del 1903-1905. Chaetognati. Pubbl. Ist. Studi. Sup. Firenze, vol. 2, p. 85-118, pl. 6-7.

Bumpus, D. \& Pierce, E. L.

1955. The hydrography and the distribution of chaetognaths over the continental shelf off North Carolina. Pap. Mar. Biol. and Ocean., suppl. to vol. 3, Deep-Sea Research, p. 92-109, figs. 1-12.

BURFIELD, S. T.

1930. Chaetognatha. Brit. Antarctic ("Terra Nova") Exped. Zool., vol. 7 , p. 203-228, pl. 1-3.

Emísson, I.

1956. Relatórios e resultados físico-químicos de três cruzeiros oceanográficos em 1956. Contr. Avulsas do Inst. Ocean., Ocean. Física, 70p., figs. 1-6.

1959. Alguns aspectos físico-químicos das águas marinhas. Ciência e Cultura, vol. 11, p. 44-54, figs. 1-6.

FAURE, M. L.

1952. Contribution à l'étude morphologique et biologique de deux Chaetognathes des eaux atlantiques du Maroc; Sagitta friderici Ritter-Záhony et Sagitta bipunctata Quoy et Gaimard. "Vie et Millieu". Bull. Lab. Arago, vol 3 (1), p. 25-43, figs. 1-6.

FOWLER, G. H.

1906. The Chaetognaths of the "Siboga" Expedition with a discussion of the synonymy and distribution of the group. "Siboga" Exped., vol. 21, p. 1-86, pl. 1-2.

Fraser, J. H.

1952. The Chaetognatha and other Zooplankton of the Scottish Area and their value as biological indicators of hydrographical conditions. Scott. Home Dep., Mar. Res., vol. 2, p. 1-52, figs. 1-4, pl. 1-3. 
FURNESTIN, M. L.

1957. Chaetognathes et Zooplancton du secteur Atlantique et Marrocain. Rev. Trav. Inst. Pêches Marit., vol. 21, (1 et 2), p. 1-356, figs. 1-104.

1960. Observations sur quelques échantillons de zooplancton d'Afrique occidentale. Bull. Inst. Afric. Noire, vol. 22, p. 142-151, figs. 1-2.

Germain, L. \& Joubin, L.

1916. Chétognathes provenant des campagnes des yachts , L' Hirondelle" et de la "Princesse Alice" (1885-1910). Res. Camp. Sci., Monaco, vol. 49 , p. 1-118, pl. 1-8.

Guatta, E. F.

1958. Investigaciones sobre Quetognatos colectados especialmente, frente a la Costa central y norte de Chile. Rev. Biol. Mar., vol. 1, p. 25-82, figs. 1-17.

Hosoe, $\mathbf{K}$.

1956. Chaetognaths from the Isles of Fernando de Noronha. Contr. Avulsas do Inst. Ocean., Ocean. Biol., n. ${ }^{\circ} 3,9$ p., pl. 1.

Pierce, E. L.

1953. The Chaetognatha over the continental shelf of North Carolina with attention to their relation to the hydrography of the area. Jour. Mar. Res., vol. 12, p. 75-92, figs. 1-4.

Súdez CaAbro, J. A.

1955. Quetognatos de los mares Cubanos. Mem. Soc. Cubana Hist. Nat., vol. 22, p. 125-180, figs. 1-7.

THIEL, M. E.

1938. Die Chaetognathen Bevölkerung des südatlantischen Ozeans Wiss. Ergeb. Deustch. Atlant. Exped. "Meteor" 1925-1927, vol. 13 , p. $1-110$.

VANNUCCI, M.

1957. On Brazilian Hydromedusae and their distribution in relation to different water masses. Bol. Inst. Ocean., vol. 8, p. 23-109, figs. 1-31.

Vannucci, M. \& Hosoe, $\mathrm{K}$.

1952. Resultados científicos do cruzeiro do "Baependi" e do "Vega" à Ilha da Trindade. Chaetognatha. Bol. Inst. Ocean., vol. 3, p. $1-30$, pl. $1-4$. 